\title{
Violence, worry and trust in the emergence of weapon- carrying
}

\begin{tabular}{|c|l|}
\hline Journal: & European Journal of Criminology \\
\hline Manuscript ID & EUC-20-0167.R2 \\
\hline Manuscript Type: & Article \\
\hline Keywords: & weapon, violence, trust in the police, fear of crime \\
\hline Abstract: & $\begin{array}{l}\text { This paper identifies longitudinal predictors of weapon-carrying in a } \\
\text { sample of 10-25 year olds in England and Wales. It conceptualises } \\
\text { weapon-carrying as anticipation of an adverse event and proposes } \\
\text { hypotheses about the origins of weapon-carrying derived from the field } \\
\text { of risk analysis. Specifically, it tests if worry about victimisation and } \\
\text { experience of violence predict later weapon-carrying and assesses the } \\
\text { worry about victimisation does not predict weapon-carrying, but } \\
\text { experience of violence does. Distrust of police and peer criminality were } \\
\text { also identified as important precursors to weapon-carrying. The study } \\
\text { provides further evidence that weapon-carrying is a product of exposure } \\
\text { to violence and criminogenic factors rather than a response to concern } \\
\text { about victimisation. }\end{array}$ \\
\hline
\end{tabular}

\section{SCHOLARONE Manuscripts}




\section{Abstract}

This paper identifies longitudinal predictors of weapon-carrying in a sample of 10-25 year olds in England and Wales. It conceptualises weapon-carrying as anticipation of an adverse event and proposes hypotheses about the origins of weapon-carrying derived from the field of risk analysis. Specifically, it tests if worry about victimisation and experience of violence predict later weapon-carrying and assesses the moderating influence of trust in the police. The results indicate that worry about victimisation does not predict weapon-carrying, but experience of violence does. Distrust of police and peer criminality were also identified as important precursors to weapon-carrying. The study provides further evidence that weaponcarrying is a product of experience of violence and criminogenic factors rather than a response to concern about victimisation.

\section{Key words}

Weapon; Violence; Trust in the police; Fear of crime 


\section{Introduction}

Illegally carrying or using a weapon in violence - typically a knife or a gun - has the potential to cause significant harm to victims and attracts severe punishments in many jurisdictions. 'Knife crime', as this behaviour is commonly termed, has dominated public discourse about crime in England and Wales in recent years, justified by increases in rates of hospital admission for violence and homicide (Office for National Statistics (ONS) 2019a, 2019b). This attention to serious violence has renewed political commitment to violence prevention as well as enthusiastic funding and use of suppression tactics, such as Stop and Search but for both longer-term preventive and shorter-term deterrent approaches to preventing weapon-carrying, understanding the early drivers of weapon-carrying is essential. European and US research has demonstrated remarkable consistency in the characteristics and behaviours of young people who report carrying a weapon illegally (Brennan 2018). However, as so many of these studies are based on cross-sectional data, it is impossible to know if these correlates preceded or followed the weapon-carrying. Naturally, identifying the common factors in the lives of young people in the time before they carried a weapon can inform both understanding and prevention of that behaviour. 
Using the best and most recently available national-level longitudinal data from England and

Wales, this paper identifies common characteristics of young people who began to carry a weapon one year later. First, it summarises the small literature on longitudinal predictors of weapon-carrying. It then frames weapon-carrying conceptually as preparation for violence and draws from the risk analysis literature on preparation for natural disaster to propose hypotheses about future weapon-carrying. Reflecting the emphasis placed on these factors in the risk analysis literature, the study focuses on worry about and experience of violence and the role of trust in authorities.

Longitudinal predictors of weapon-carrying

Across the literature, commonly-cited correlates of weapon-carrying are experience of violent victimisation, perpetration of violence, fear of victimisation, peer criminality, higher rates of peer and community weapon-carrying, low trust in the police and community violence (Brennan and Moore 2009; Brennan 2018; Bègue et al 2016; McVie 2010). As the literature is largely based on cross-sectional studies, little progress has been made to determine the order in which weapon-carrying and its correlates appear. The lack of longitudinal research in this area means that we are some distance from knowing the causes of weapon-carrying. The 
following short section describes the most widely tested longitudinal associations, which relate to worry, fear, violence and the role of peers.

Worry, fear and likelihood

A popular theory of weapon-carrying is that if a person fears for their own safety they might arm themselves in response (Brennan and Moore 2009; McVie 2010; Harding 2019). This suggests a causal line from emotion to behaviour that is often inferred, but rarely observed. Given that the prevalence of high levels of worry about crime (ONS 2017a) is at least double that of any weapon-carrying in a year and that the demographic profile of those who worry most about crime (ONS 2017b) is inconsistent with those who are most likely to carry a weapon, it is unlikely that this simple explanation of weapon-carrying will have strong empirical support. Research confirms this: cross-sectional quantitative studies have, in general, failed to find robust evidence that fear or worry about victimisation predicts illegal weapon-carrying (Brennan 2018). Furthermore, the evidence for a longitudinal relationship between concern about future victimisation and weapon-carrying suggests only modest associations. However, this evidence is complicated by the conceptual differences between fear, worry and perceived likelihood that are regularly discussed in criminological research 
(Jackson 2005; Farrall et al 2009) and the narrative accounts of weapon-carriers who claim that they only carry weapons for self-defence (Traynor 2016; Harding 2019).

The longitudinal evidence that perceived risk of violence causes or, at least, precedes weapon-carrying is mixed. Using a three-year lag panel study in Mexico, Braakman (2012) observed the impact of community-level violence risk - measured using self-reported experience of victimisation and perceptions of risk - on later weapon-carrying by males: perceived risk of victimisation did not predict weapon-carrying, but direct experience of violent victimisation did. In a sample of early teens in the southwestern United States, perceived risk of victimisation predicted weapon-carrying at six-month follow-up, but fear of victimisation did not (Melde et al, 2009). However, it is noteworthy that the study measured weapon-carrying using the question "have you ever carried a hidden weapon for protection", which may have biased respondents towards a protective justification for their weaponcarrying and, by referring explicitly to protection and hidden weapons, could have led some respondents to legitimately exclude some weapon-carrying.

This overview is not exhaustive, but it is indicative of the overall literature, and a longitudinal association between fear and weapon-carrying has not been tested with a European 
population. Nonetheless, the international literature suggests that negative affect - worry or fear - alone are not strong longitudinal predictors of weapon-carrying.

\section{Violent experience}

The theoretical explanation for a correlation between experience of violence and weaponcarrying is that as a person experiences more violence, that violence becomes more serious and starts to involve weapons (Brennan and Moore 2009). The correlation between experience of violence and weapon-carrying is, arguably, the most strongly supported association in a literature that relies largely on cross-sectional data. The temporal nature of this association means that this theory is well-suited to longitudinal analysis and the small literature employing longitudinal methods to test the association is consistent in its support for this link.

Before reviewing this literature, it is important to note that some work in this area has attempted to separate violent experience into offending and victimisation. However, making a clear distinction between the two outcomes is conceptually problematic and subjective: many violent encounters do not have clear victims and perpetrators or winners and losers (Collins 2008) and the items used to measure these two concepts in most social surveys are not sufficiently refined to treat the two as distinct experiences. Consequently, for the purposes of 
this review and the subsequent analyses in the paper, victimisation and perpetration of violence are each treated as experience of violence; the merits of doing so are discussed later ${ }^{1}$.

Spano et al (2012) examined the influence of perpetrating, experiencing or witnessing violence on weapon-carrying in a sample of African Americans adolescents and young adults living in highly deprived neighbourhoods. Respondents were surveyed twice (the time between surveys was not stated but appears to be less than one year). Adjusting for demographic factors and gang membership, they found that perpetrating violence mediated the relationship between witnessing violence and later weapon-carrying. Dijkstra et al (2010) found that trait aggression - measured through a combination of violent cognitions, thoughts and behaviours - predicted weapon-carrying over time. Steinman and Zimmerman (2003) found that frequency of violence was associated with persistence of weapon-carrying.

\footnotetext{
${ }^{1}$ In addition, supplementary analyses were undertaken to model the independent influence of violence perpetration and violent victimisation; the $\mathrm{R}$ code to support are available as an appendix.
} 
From these there is strong evidence that violence precedes weapon-carrying and that the severity of violence, which comes to include weapon-carrying, escalates with experience (Hagan and Foster 2001).

Interpersonal factors and the role of peers in weapon-carrying

There is good evidence that having peers who get in trouble with the police and who carry weapons influences weapon-carrying (e.g. Brennan 2018; Djiskstra et al, 2010). In general, the explanation for this mechanism is that the emergence of weapon-carrying in these conditions reflects increasing involvement in delinquency and crime. Although this literature is dominated by American gang research, peer influence and weapon carrying contagion among peers has also been identified in samples with no gang affiliation.

Here, the theoretical mechanism is that weapon-carrying is an accompaniment to an individual's criminal lifestyle that is facilitated by criminal interpersonal factors. The US literature on this association has predominantly focused on gang membership (e.g. Bradshaw et al. 2013; Tigri et al. 2016), which may have strengthened the observed relationship through the presence of a confounder such as criminal enterprise. However, the research that has not imposed a gang membership frame on this association has still found evidence of a longitudinal influence of peers on weapon-carrying. 
In a sample of high-risk adolescent males, Dijkstra et al (2010) found evidence of a

longitudinal influence of peers on frequency of weapon-carrying and a high consistency in the frequency of weapon-carrying over time. Similarly, Lizotte et al (2000) found that, in early adolescence, gang membership and prior gun-carrying predicted gun-carrying one year later. Steinman and Zimmerman (2003) sought to differentiate between episodic and persistent gun-carriers in a sample of African-American high school students in the US and found that male gender, the number of adults they knew who carried a gun, frequency of fighting, marijuana use and drug selling (all at a 13/14 year old baseline) distinguished between non-carriers and episodic carriers at four year follow-up. Frequency of fighting and drug selling distinguished between episodic and persistent gun carriers. In both cases, contrary to much other research in this area, peer weapon-carrying did not predict respondent weapon-carrying.

Tigri et al (2016) using four waves of a large longitudinal survey of young people in the US (aged between 12 and 16 years at baseline) to examine the influence of gang membership, delinquency and current weapon-carrying on weapon-carrying one year later. Controlling for demographic factors and contemporary peer gang membership, respondent gang membership and delinquency, they found limited evidence of a longitudinal gang membership influence. 
The evidence indicates that, if not causal, having criminal peers is a good predictor that a person will carry a weapon in the future and that the direction of the relationship is that peer criminality tends to precede weapon-carrying.

Weapon-carrying and risk analysis

The evidence summarised above is convincing in its consistency, but also illustrates the range of factors contribute to weapon carrying. It also emphasises how little success there has been in drawing these individual factors together into a coherent theory that explains why some people carry a weapon illegally.

Individual factors may contribute to weapon-carrying behaviour, but unidimensional explanations, such as fear, self-defence or aggressive personality fail to appreciate that the drivers of weapon-carrying can be simultaneously defensive, offensive and demonstrative (Brennan 2017). Conceptualising this behaviour as solely the product of one of these three drivers forces theory down a narrow and unrealistic path that does not reflect the complexity of lives surrounded by violence. One way to free theories of weapon-carrying is to think about this behaviour as reflecting anticipation of violence rather than as being the result of specific motivations, i.e. viewing weapon-carrying as preparation for a dangerous event in a 
similar way to how individuals view and respond to the threat of communicable disease or

natural disaster.

Like criminology, the academic field of risk analysis is concerned with individual

vulnerability and the preparation for future adversity (Short 1984). Given that they swim in similar pools of rare and adverse human experience, it is surprising how infrequently the fields meet. Some links have been made between the areas, such as work on risk analysis and fear of crime (Jackson 2006; Jackson and Gouseti 2016; Ferraro 1995; Warr 2000) and earlier research on the sociology of risk as it applies to crime (Short 1984). There are many other under-exploited connections that could advance our understanding of how individuals and groups imagine and respond to external threat and how they act in the aftermath of adversity. Like criminology, risk analysis has demonstrated that people think and act in ways that are inconsistent with their vulnerability to hazardous events (Slovic 1994; Hale 1996; Jackson 2007). Compared to criminology, risk analysis has done more to show how factors can interact to affect how people protect themselves from hazards. Criminology and risk analysis have much to gain from an acknowledgement of the similarity in the phenomena they study and from cross-pollination of their theories and evidence. 
The next section uses a short review of the risk analysis literature to draw parallels with weapon-carrying and to demonstrate where the risk analysis literature can advance criminological knowledge about threat perception and preparation for uncertain adversity. It first describes a naive rational model for understanding and responding to external threat before identifying crucial factors that affect this mechanism: experience and trust in authorities.

Perceiving vulnerability and responding to threat

Risk perception is a judgement an individual makes about their vulnerability to a future external hazard, such as a natural disaster or communicable disease (Slovic 1987) and risk preparation is an action about that future hazard, such as taking out insurance, purchasing flood defences or wearing protective clothing. Risk perception incorporates subjective and objective information and probabilistic thinking into a judgement about a person's vulnerability to an uncertain future hazard. A naïve rational model of risk perception infers that a person assesses their vulnerability - in terms of the probability and likely harm - to an adverse event, which generates a corresponding amount of threat salience. In turn, this threat salience will lead to activity to prepare for, mitigate or avoid that event. However, a systematic review of this literature shows that this two-step model of risk analysis has limited 
supporting evidence (Wachinger et al 2013), particularly when it comes to translating risk

perception into risk preparation.

Direct experience is a very important influence in risk analysis and there is good evidence that experience leads to diverging models of risk preparation (Wachinger et al 2013): those with little or no experience of the hazard rely on a combination of internal and external factors to navigate the relationship between risk perception and risk preparation; for others, experience of the threat is the main driving force in preparation. However, even among those with prior experience of the threat, other factors appear to play a role. Wachinger et al (2013) show that trust in authorities can influence the relationship between feeling vulnerable and probability of preparing for the event.

Short (1984) notes that institutions (i.e. those with responsibility for knowing about and protecting the community from hazards) are highly influential in individual risk perception. Accordingly, in the field of risk analysis, experts and institutions loom large. Predicting and preparing for natural disaster requires cooperation and resources that are beyond individuals or small groups. Consequently, people must trust experts and authorities to provide accurate information about the probability, severity and urgency of natural disasters and to implement appropriate security and protection for communities (Slovic et al 1982; Clemen and Winkler 
1999). People who do not trust authorities - that is, do not trust them to provide accurate

information about and protection from a threat - generally feel more vulnerable to that threat

(Wachinger et al 2013).

Although trust in authorities is, normatively, a desirable trait, Wachinger et al (2013) found that trust in authorities is an obstacle to preparing for disaster: people who trust the authorities to protect them are often the least prepared for disaster. Unpacking this observation reveals its logic: ceding responsibility for one's own safety to another party suppresses the motivation to prepare for the adverse event. In reverse, if an individual does not trust the authorities to protect them, they are more likely to feel responsible for their own safety. Clearly, a parallel with weapon-carrying can be drawn here: if a person expects to be involved in violence and does not believe the authorities can prevent it, a weapon can prove useful.

Cross-sectional research has found a consistent negative relationship between weaponcarrying and trust in authorities (Brennan 2018; Bègue et al 2016). This association has been alluded to many times (Lizotte et al 2000; Harcourt 2006). Although trust in authorities most importantly in this case, the police - has several dimensions (Jackson and Bradford 2010), the obvious aspect of trust in this mechanism is trust in police competence, i.e. that 
police are competent to protect the individual from harm through distal (by creating a safe

environment) and proximal measures (situational crime prevention activity). Unfortunately, the relationship between trust and weapon-carrying does not appear to have been tested longitudinally. Such analysis would be useful as, theoretically, carrying a weapon may harm an individual's trust in authority, but could also expose them to other factors that damage this trust.

Applying the risk analysis evidence to the behaviour of weapon-carrying, two models emerge. Firstly, having less trust in the authorities should be associated with greater worry about victimisation (risk perception; H1) but worry about victimisation should be only modestly associated with greater likelihood of carrying a weapon (risk preparation; H2). That relationship should be moderated by trust in the authorities with a more positive relationship between worry and weapon-carrying present in those who have less trust in authorities (H3). Secondly, the extent of experience of violence should be associated with increased probability of weapon-carrying (H4) and that relationship should be moderated by trust, with a stronger relationship between experience and weapon-carrying among those who have less trust (H5). 
Methods

Sample

Between 2003 and 2006, the peak of recorded serious violence in England and Wales, 13,538

people in England and Wales aged ten years and over completed the Offending, Crime and

Justice Survey (OCJS). The survey asked respondents about their offending behaviour,

experience of victimisation and attitudes towards a range of issues, including their own

neighbourhoods and the police in the past year. The OCJS employed a mixed cross-sectional and longitudinal design: approximately one-third of respondents who took part in 2003 were surveyed each subsequent year. The survey over-sampled young people and had a mean age of 23.2 years and a median age of 18 years. For the purposes of this study, the sample was limited to the 4,234 respondents aged 10-25 years in 2005 who completed the survey in 2005 and 2006. Linking the two waves of data using each respondent's unique reference number created a longitudinal data set. Hereafter, responses from the 2005 wave are described as $t 1$ and responses from the 2006 wave are described as $t 2$. Although continuing and habitual weapon-carriers are likely to be of particular interest to those involved in the immediate prevention and suppression of weapon-carrying, this study is concerned with understanding 
the initiation of weapon-carrying. Therefore, the sample is limited to those who did not report carrying a weapon in $t 1$.

\section{Measures}

Carrying a weapon: Respondents were asked if they had carried (a) a knife or (b) a gun with them "for their own protection, for use in crimes or in case they got into a fight". These two variables were combined to create a single binary measure that represented whether or not someone had carried a gun or knife in that year. Weapon-carrying in $t 2$ was the outcome variable and weapon-carrying in $t 1$ was used to filter the sample so that it only included people who initiated weapon-carrying in $t 2$.

Direct experience of violence: Frequency of recent violent behaviour in $t 1$ was ascertained by asking respondents if they had done any of the following: "Used force or violence on someone without injuring them", "Used force or violence on someone on purpose and injured them" in the previous 12 months. An affirmative response to this question was followed by an item asking about the frequency of this violence. This was collated into a single variable that ranged from 0 (no violence) to 6 (six or more incidents).

Frequency of recent violent victimisation: Recent violent victimisation in $t 1$ was ascertained by asking respondents if, in the previous 12 months, anyone had used force against them on 
purpose and, if so, how many times. A maximum score for this variable (six) was imposed to indicate six or more incidents of violent victimisation; the minimum possible score was 0 , which indicated no violent victimisation.

The two variables were added to create a variable (range 0-6) that represented 'direct experience of violence'. Although combining these variables is unusual, there are empirical and conceptual reasons for doing so: the correlation between frequency of violence perpetration and violent victimisation is high $(r=0.37)$ suggesting that the two are closely related - it is often difficult to know if an individual regarded themselves as a victim or a perpetrator in a violent incident - and the theory under examination is based on experience of violence rather than self-protection or offensive purposes; removing this distinction creates a more holistic and valid measure of experience of violence.

Worry about being a victim of violence was measured by combing the responses to two items: "How worried are you about being mugged or robbed" and "How worried are you about being physically attacked by strangers". Responses in the original survey were coded as an ordinal variable with higher scores indicating lower levels of worry ('Very worried', 'Fairly worried', 'Not very worried' and 'Not at all worried'). In both cases, responses were recoded so that a higher score indicated greater degree of worry and the item ranged from 2 to 8 . To 
aid interpretability of the regression analyses, the variable was rescaled to have a range of 0 to 6 .

Trust in the police for $t 1$ and $t 2$ was measured by asking respondents how much they trust police in their area. Responses were coded as an ordinal variable with higher scores indicating lower levels of trust (A lot; A fair amount; Not very much; Not at all). As a very small number of respondents indicated that they did not trust the police at all, 'Not very much' and 'Not at all' were collapsed into a single category.

Peers in trouble at $t 1$ was measured by asking respondents about the proportion of their close friends who had been in trouble with the police in the previous 12 months. Respondents could respond using a five-point scale with higher scores indicating a greater proportion (None of them; A few of them; Quite a lot of them; Nearly all of them; All of them). Respondents who indicated that nearly all or all of their friends had been in trouble with the police accounted for $0.3 \%$ of the sample. Consequently, to reduce these small numbers biasing the model estimates, the responses 'Quite a lot of them', 'Nearly all of them' and 'All of them' were collapsed into a single category, which accounted for approximately $1 \%$ of the sample. 
Statistical analysis and reproducibility

The OCJS data sets were downloaded from the UK Data Service archive (Home Office 2008a; 2008b) and are available without charge for non-commercial use. The R syntax to recreate the data linkage and subsequent analyses are available here: $<<$ to add $>>$. The data were analysed in R 4.0 (R Core Team 2020) using RStudio (1.2.5033, RStudio Team 2018). R packages 'tidyverse' (Wickham et al 2019) and 'naniar' (Tierney et al 2020) were used to clean the data.

Missing data $(0.12 \%$ in the outcome variable and up to $5.6 \%$ for the variable relating to the proportion of peers in trouble with the police) were multiply imputed using the 'mice' package (van Buuren and Groothuis-Oudshoorn 2011) to create 20 complete data sets and results of analyses were pooled to provide estimates and standard errors. Descriptive statistics were derived from a single, randomly selected imputed data set.

Hypothesis 1 (less trust in authorities predicts greater worry about victimisation) was tested by an ordinary least squares regression of distrust of the police at $t 1$ on worry about victimisation at $t 1^{2}$. Hypothesis 2 (worry about victimisation has a weak relationship with

\footnotetext{
${ }^{2}$ Because of the unusual distribution of the outcome variable and the origin of its components as ordinal variables, the relationship was also modelled using ordinal logistic regression (using the 'MASS' package (Venables and Ripley 2002)). The models produced very similar
} 
future weapon-carrying) was tested using logistic regression. Hypothesis 3 (trust moderates

the relationship between worry and future weapon-carrying) was tested by statistically

adjusting for trust in the preceding model. Hypothesis 4 (experience of violence predicts

future weapon-carrying) was tested using logistic regression and the impact of trust on this

relationship (hypothesis 5) was modelled by statistically adjusting for distrust in the police

into the preceding model.

As there are several important potential confounders to consider - sex, age, area crime levels and peer criminality - these covariates were also included in subsequent models.

The effect of differing levels of distrust of the police on the relationship between experience of violence and weapon-carrying was visualised using 'ggplot2' (Wickham 2016), 'ggiraph' (Gohel and Skintzos 2019) and with the addition of peers in trouble with the police, which also employed the 'lemon' package (McKinnon-Edwards 2020) to visualise the relationships as individual facets according to proportion of peers in trouble.

results and the ordinal logistic regression model can be found in the 'Supplementary analyses' appendix. 
Results

Table 1 provides descriptive statistics. Variables relating to the experience of respondents in 2005 are indicated by the subscript $t 1$. After limiting the sample to respondents who did not carry a weapon in the earlier wave of the survey, slightly under $2 \%$ of respondents reported carrying a weapon in the $t 2$ survey period. One in four experienced or perpetrated violence and the median level of worry about personal victimisation was two (range 0 (low worry) - 6 (higher worry)). The median level of distrust of the police was "Some trust in the police" and $80 \%$ of respondents had no friends in trouble with the police.

\section{TABLE ONE}

Table 2 presents two analyses of the relationship between distrust of the police and worry about crime. Both models demonstrate that when a respondent had lower trust in the police, they were also likely to be more worried about violent victimisation than other respondents. The models (model 1-1 used ordinary least squares regression and model 1-2 used ordinal logistic regression) do not agree on the pattern of the relationship between trust in the police and worry about victimisation, but both indicate that high levels of distrust of the police were associated with higher levels of worry. The most conservative estimate - based on the 
ordinary least squares model - of the relationship is that each additional level of distrust was associated with an increase in worry of just 0.1 (on a 7-point scale).

Table 3 describes four models that tested hypotheses 2 and 3, presenting beta coefficients and confidence intervals. Model 2-1 is the bivariate relationship between worry and weaponcarrying. Model 2-2 is relationship between worry and weapon-carrying when statistically adjusting for trust in the police. Model 2-3 estimates the interaction between worry and trust in the police in relation to weapon-carrying (hypothesis 3) and model 2-4 assesses the relationship between worry and weapon-carrying when statistically adjusting for the influence of distrust of the police and the proportion of peers in trouble with the police, gender, age and area crime deprivation.

\section{TABLE TWO}

TABLE THREE

Model 2-1 demonstrates that there was no relationship between worry about victimisation during $t 1$ and weapon-carrying during $t 2$. Model 2-2 demonstrates that level of trust in the police did not affect the relationship between worry and weapon-carrying, which was supported by model 2-3, which found no relationship between weapon-carrying and the interactions between worry about victimisation and trust in the police. Statistically adjusting 
for the influence of a respondent's peers being in trouble with the police did not influence the relationship between worry about victimisation and weapon-carrying, although adjusting for age, sex and area crime deprivation did results in a stronger relationship between worry and future weapon-carrying, but not to the extent that the relationship was statistically significant. Table 4 describes the models that tested hypotheses 4 and 5, presenting beta coefficient and confidence intervals. Model 3-1 demonstrates that the amount of experience of violence at $t 1$ was a strong predictor of weapon-carrying at $t 2$. This effect remained in the second model, which indicated that, for respondents who experienced no violence, having little or no trust in the police was associated with a $27 \%$ higher probability of carrying a weapon during $t 2$. Model 3-3 demonstrates that the interaction between experience of violence and trust in the police was not a statistically significant predictor of weapon-carrying at $t 2$. This is illustrated in Figure 1 in the approximately parallel slopes the predicted probability lines: those with less trust in the police who did not experience any violence had a higher likelihood of carrying a weapon and, as the influence of violence on weapon-carrying increased, likelihood of weapon-carrying remained approximately parallel. Model 3-4 demonstrates that, statistically adjusting for the proportion of peers in trouble with the police, direct experience of violence and having little or no trust in police remained statistically significant predictors of later 
weapon-carrying and Model 3-5 demonstrates that those relationship remain following

statistical adjustment for age, sex and area crime deprivation. The strong influence of peers in trouble with the police on the likelihood of carrying a weapon during $t 2$ is illustrated in

Figure 2, which shows large differences in likelihood of weapon-carrying across this category and steep effects of violent experience on weapon-carrying regardless of respondent trust in the police if a respondent had many peers in trouble with the police.

\author{
TABLE FOUR
}

FIGURE ONE

FIGURE TWO

\title{
Discussion
}

This paper capitalised on the availability of longitudinal data to observe and compare patterns in the lives and attitudes of young people in the year before some began to carry a weapon. The paper conceptualised weapon-carrying as anticipation of an adverse event - violence rather than framing is as a behaviour motivated by a specific goal, such as aggression, selfdefence or identity management. Drawing a connection between preparing for violence and preparing for natural disaster, the paper proposed and tested hypotheses about the origins of weapon-carrying that were derived from literature from the field of risk analysis. 
Firstly, it was hypothesised that distrusting the police would co-occur and correlate with worry about victimisation. The analysis supported this hypothesis and the finding is consistent with the risk analysis literature that has shown a negative relationship between trust in authorities and risk perception. The analysis did not support hypotheses two and three, which proposed that worry about victimisation is associated with later weapon-carrying and that this relationship is moderated by the extent to which a respondent trusted the police, respectively. There was no bivariate relationship between worry and weapon-carrying and adjusting for trust in the police and proportion of peers in trouble with the police in subsequent models did not change this relationship. Therefore, the evidence indicates that worry about victimisation is not a direct cause of weapon-carrying one year later and that worry about violence and trust in the police do not interact to affect the emergence of weapon-carrying.

Hypotheses four and five proposed that experience of violence is a predictor of later weaponcarrying. The bivariate analyses indicated that each incident of violence (up to six or more incidents) was associated with a $6 \%$ increase in the probability that the respondent would carry a weapon the following year. Statistically adjusting for the influence of trust in the police at $t 1$ did little to affect the relationship between experience of violence at $t 1$ and 
weapon-carrying at $t 2$, although there was a small moderating effect. Figure 1 demonstrates that experience of violence had a more intense influence on later weapon-carrying if the respondent did not trust the police compared to those who did. This is consistent with the findings in the risk analysis that trust in authorities is associated with reduced preparedness for disaster. However, as indicated in the cross-sectional research, weapon-carrying often cooccurs with other illegal or criminogenic behaviours. Consequently, it was important to consider the influence of confounding variables on the relationship between experience of violence, trust in the police and weapon-carrying. When the proportion of peers in trouble with the police at $t 1$ was included in a model, the relationship between experience of violence and weapon-carrying and trust in the police and weapon-carrying was reduced considerably. Interpreting coefficients in a regression model with multiple covariates can be complicated and figure 2 provides a clearer illustration of the influence of peers on weapon-carrying. The consistency in the order of lines (solid lines - representing high degrees of trust always being the bottom line and the long dashed line - representing little or no trust - always on top) shows that, regardless of peer influence, distrust of the police was associated with higher probability of later weapon-carrying. Also, regardless of peer characteristics, direct experience of violence was associated with increased probability of later weapon-carrying. 
Panel 3 of figure 2, which is made up of respondents for whom most or all of their peers were in trouble with the police at $t 1$, demonstrates that the probability of later weapon-carrying rose sharply as direct experience of violence increased. However, while this may appear to be a stark difference, it is the same doubling of the probability of carrying a weapon that can be observed in the other groups but from a higher starting position. In simple terms, trust in the police and direct experience increased the likelihood of future weapon-carrying, but their influence was very modest compared to that of having peers in trouble with the police. The study provides further evidence that worry about victimisation does not predict weaponcarrying longitudinally. That does not mean people involved in violence are not concerned about victimisation - they have repeatedly said they are (Harding 2019) - but it does suggest that this concern is not a direct cause of their weapon-carrying over a significant length of time. One interpretation of this finding is that weapon-carriers play down their concerns about victimisation in social surveys, leading to a measurement error that hides a real effect of worry on weapon-carrying. Alternatively, worry about victimisation may be too shortlived to create a detectable effect on weapon-carrying one year later. If this were true, a crosssectional analysis may be a better test of the hypothesis. While this specific relationship has not been tested, Brennan (2018) found that no relationship existed between feelings of safety 
and weapon-carrying after statistically adjusting for criminogenic factors such as violence

and peers in trouble with the police. Finally, it may simply be that worry about victimisation does not directly cause a person to carry a weapon. Perhaps the people who are concerned about victimisation choose other, less violent ways to manage this concern, such as avoidance of potentially dangerous situations or they live with this worry and do nothing extraordinary to prepare for violence.

As noted above, the probability of weapon-carrying for the sample increased by $6 \%$ for each additional incident of violence (up to a maximum of six or more incidents). This finding is consistent with evidence from the risk analysis literature that experience of a past adverse event increases preparedness for similar events in the future. However, it does not fully explain the mechanism. A plausible interpretation is that past experience of violence is an indicator of future experience of violence, leading some individuals to arms themselves in anticipation. Importantly, model 3-4, demonstrates that the effect remains even after statistically adjusting for the influence of having peers in trouble with the police. This suggests that the effect of experience of violence on weapon-carrying is independent of a criminal lifestyle. 
This study is the first attempt to model the longitudinal impact of trust in the police on weapon-carrying. It demonstrates a weak relationship that should not be seen as independent of the influence of peers or wider criminogenic factors and does not account for past criminal experience. Figures 1 and 2 clearly shows the intertwined relationships between peer groups, violence and trust and the study design is not sufficiently precise to separate them. It is also important to note that the study hypotheses were based on trust in police competence but the item in the OCJS used to measure trust did not specify trust in police competence. In addition, the issue of causal direction cannot be resolved with the available data: it is possible that a factor, such as history of offending, could explain both trust in the police and weaponcarrying. New data linkages between police data and longitudinal surveys (Boyd et al 2020) will allow this to be addressed in the future.

The analysis demonstrates that respondents with less trust in the police were, at the same time, more worried about being a victim of violence than other respondents, which is consistent with the risk analysis and criminological literature (Visser et al 2013; Krulichova 2019). Worry about victimisation did not predict weapon-carrying independently or when it was interacted with trust in the police. Therefore, although trust in the police was associated with later weapon-carrying, it is unlikely that the mechanism by which distrust affected 
weapon-carrying - if it did - was through creating heightened concern about victimisation.

This is supported by the finding that the relationship between trust in the police and weaponcarrying in model 2-4 was moderated considerably by statistically adjusting for the influence of having peers in trouble with the police. A broadly similar pattern was observed in models 3-3 and 3-4 whereby the longitudinal influence of trust in the police is reduced by the inclusion of peers in trouble with the police in the model, although in these models, the main variable of interest, direct experience of violence, was influential in the initiation of weaponcarrying.

The low prevalence of weapon-carrying across the study waves prohibited the development and testing of a more sophisticated causal model of weapon-carrying, but an important study for the future will be to model the temporal order of peer contact with criminal justice, trust in the police and experience of violence. It is necessary to exercise caution in interpreting effect sizes in regression analyses with multiple variables, but the magnitude of the relationship between weapon-carrying and peers in trouble and its impact on the other covariates suggests that there is a strong peer influence in weapon-carrying. This influence may not be direct peer pressure to carry a weapon but may simply reflect selection effects in peer groups, i.e. that weapon-carrying emerges over time as a product of experience of crime. 
This is also consistent with the finding that the extent of violence experienced predicts later weapon-carrying.

The hypothesis that trust in the police moderates the relationship between experience of violence and weapon-carrying was derived from the literature on risk analysis rather than from the criminological literature. It has been a useful vehicle for theoretically deriving the hypotheses test herein, but it is important to reflect on the extent to which this translation is a valid one. The mechanism in the risk analysis literature implies that people who have been failed by the protective system of authorities and technology in the past take safety into their own hands. The comparison here with weapon-carrying is appealing in its clarity, but possibly overlooks some of the nuanced differences between preparing for disaster and preparing for violence and the role of authorities in the two scenarios. Firstly, it is important to note that the populations who prepare for disaster - and from whom the research data is derived - and who prepare for violence are very different in age and may have very different decision-making processes. As adolescents assessment of risk is disproportionately affected by information from peers (Albert et al 2013), peer criminality and peer experience may be more important in assessing worry about crime and risk perception for the sample of this study compared to the typical samples in the risk analysis literature. Unfortunately, 
appropriate measures were not available in the OCJS to assess this difference and, although models were statistically adjusted for age, the oldest participants were just 25 years of age at t1. Secondly, 'preparing' for natural disaster has few moral or legalistic implications. The same cannot be said for weapon-carrying, which can have serious legal consequences and, at best, is morally ambiguous. Furthermore, the act of 'preparing' for natural disaster is wholly defensive - one cannot attack an earthquake - but weapon-carrying can be simultaneously offensive and defensive. Thirdly, in disaster management, the institutions that protect the population are formal, but in the case of violence, it is not only formal organisations like the police who can protect an individual from violence. Peers, or even gangs, can form the basis of informal networks that provide protection from adversity, so measuring the role of the authorities in preparation for violence does not cover the whole range of protective entities. Finally, but not exhaustively, compared to disaster planning, weapon-carrying - at least through the widespread availability of kitchen knives - has fewer tangible costs, so the facilitators and barriers to weapon-carrying and disaster planning differ.

\section{Limitations}

While this study has identified some correlates of the lives of young people who go on to carry a weapon, the survey data only provides a glimpse of what has informed that behaviour 
and the relatively small number of weapon carriers prohibited analysis of different patterns of weapon-carrying initiation across factors like gender, age and area crime deprivation.

Information about peer weapon-carrying was not available nor was detailed information about their neighbourhood, both of which would allow more acute understanding of how interpersonal and environmental factors have shaped the emergence of weapon-carrying. In addition, we know little about how perception of threat is generated in this population. Fear of crime (Curiel and Bishop 2019) and 'hot spot' awareness research (Rengert and Pelfrey 1997 ) has shown that personal dispositions and experience, vicarious experience, rumour, social and traditional media all contribute to perceptions of violence within an environment. Longitudinal studies have advantages over cross-sectional studies in terms of establishing a line of causality. However, the possible range of time between an event reported in the baseline and an event reported in follow-up survey is two days to two years. This paper models the emergence of weapon-carrying over one year, but it is likely that, for some of the respondents, the factors that led to weapon-carrying unfolded over much shorter periods. While the time between two events is likely to be normally distributed, the limitation that this design is poorly suited to model the effect of proximal factors should be recognised and, in particular, there are limits in the extent to these findings can be operationalised for 
intervention or prevention. This is an important limitation to consider in relation to the effect of worry about victimisation because an extreme emotional state can emerge rapidly, lead to an extreme behaviour, then return to a more stable state. In the absence of data that asks respondents about their emotional state in the moments before a particular action, assessing the longitudinal impact of a general state of worry about victimisation is the best that can be achieved.

Data collection for this study was conducted in 2005 and 2006, which may limit the extent to which the observations reflect those of young people almost a generation later. The OCJS remains the most comprehensive and most recent national longitudinal survey of offending behaviour in England and Wales and was conducted concurrent with rates of violence that are similar to contemporary patterns. Furthermore, little has changed in the interim to improve the lives of young people in England and Wales (UNICEF, 2020). By extension, the realities of violence, vulnerability, trust in the police and peer influence that this study has examined are likely to remain relevant. As a counter-argument, new methods of communication, changes in leisure activities and lower overall crime rates today and higher rates of alcohol consumption in the mid-2000's are ways in which period and cohort effects may differ 
between the 10-25 year olds populations of 2005 and 2020, potentially limiting the extent to which these results are generalisable.

\section{Conclusion}

This study has advanced on cross-sectional social-ecologically-informed models of weaponcarrying (Brennan 2018) by adding a longitudinal component to the evidence. It has shown that, while worry about victimisation has little relationship with future weapon-carrying, experience of violence, peer criminality and low trust in the police are predictive of weaponcarrying one year later. Therefore, weapon-carrying is more indicative of a significant longitudinal pattern of experience of violence than a self-defence response to threat. These findings have implications for policy makers and for those engaged in violence prevention activities. It suggests that interventions that seek to reduce weapon-carrying, particularly if a person has already begun this behaviour, are too late and that the seeds of serious harm that results from weapon-carrying are sown in cumulative violence experienced and perpetrated at a younger age. Consequently, early intervention with those at risk of involvement in violence is more likely to have success than later interventions with weapon carriers. Finally, the 
influence of peers in the emergence of weapon-carrying is an urgent topic for investigation and, potentially, a valuable route to the prevention of serious violence. 


\section{References}

Albert D, Chein J and Steinberg L (2013) The teenage brain: Peer influences on adolescent decision making. Current Directions in Psychological Science 22(2): 114-1120.

Bègue L, Roché, S and Duke AA (2016) Young and armed: A cross-sectional study on weapon carrying among adolescents. Psychology, Crime and Law 22(5): 455-472.

Boyd A, Teyhan A, Cornish R, Croft J, Thomas R, Brennan, IR et al. (2020) The potential for linking cohort participants to official crime records: A pilot study using the Avon Longitudinal Study of Parents and Children (ALSPAC). Wellcome Open Research, 5:271 (https://doi.org/10.12688/wellcomeopenres.16328.1).

Braakmann N (2012) How do individuals deal with victimization and victimization risk? Longitudinal evidence from Mexico. Journal of Economic Behavior and Organization 84(1): 335-344.

Bradshaw CP, Waasdorp TE, Goldweber A and Johnson SL (2013) Bullies, gangs, drugs, and school: Understanding the overlap and the role of ethnicity and urbanicity. Journal of Youth and Adolescence 42(2): 220-234. 
Brennan IR (2017) High stakes: The role of weapons in offender decision-making. In W

Bernasco, H Elffers and J-L van Gelder (Eds.) Oxford Handbook of Offender Decision-

Making (pp. 421-444). Oxford: Oxford University Press.

Brennan IR (2019) Weapon-carrying and the reduction of violent harm. British Journal of

Criminology 59(3): 571-593.

Brennan IR and Moore SC (2009) Weapons and violence: A review of theory and research.

Aggression and Violent Behavior 14(3): 215-225.

Clemen RT and Winkler RL (1999) Combining probability distributions from experts in risk analysis. Risk Analysis 19(2): 187-203.

Collins R (2008) Violence: A Micro-Sociological Analysis. Princeton: Princeton University Press.

Curiel RP and Bishop S (2018) Fear of crime and the impact of different distributions of victimisation. Palgrave Communications 4, 46.

Dijkstra JK, Lindenberg S, Veenstra R, Steglich C, Isaacs J, Card NA et al. (2010). Influence and selection processes in weapon carrying during adolescence: The roles of status, aggression, and vulnerability. Criminology 48(1): 187-220. 
Farrall S, Jackson J and Gray E (2009) Social Order and Fear of Crime in Contemporary

Times. Oxford: Oxford University Press.

Ferraro KF (1995) Fear of Crime: Interpreting Victimization Risk. Albany: State University

of New York Press.

Gohel D and Skintzos P (2019) ggiraph: Make 'ggplot2' graphics interactive. R package version 0.7.0. https://CRAN.R-project.org/package=ggiraph

Hagan J and Foster H (2001) Youth violence and the end of adolescence. American Sociological Review 66(6): 874-899.

Jackson J and Gouseti I (2016) Threatened by violence: Affective and cognitive reactions to violent victimization. Journal of Interpersonal Violence 31(18): 2987-3016.

Hale C (1996) Fear of crime: A review of the literature. International Review of Victimology 4(2): 79-150.

Harcourt B (2006) Language of the Gun: Youth, Crime, and Public Policy. Chicago: University of Chicago Press.

Harding S (2019) Getting to the point? Reframing narratives on knife crime. Youth Justice 20(1-2): 31-49. 
Home Office, National Centre for Social Research, BMRB. Social Research. (2008a).

Offending, Crime and Justice Survey, 2005. [data collection]. 3rd Edition. UK Data

Service. SN: 5601, http://doi.org/10.5255/UKDA-SN-5601-1

Home Office, BMRB, Social Research, National Centre for Social Research. (2008b).

Offending, Crime and Justice Survey, 2006. [data collection]. 2nd Edition. UK Data

Service. SN: 6000, http://doi.org/10.5255/UKDA-SN-6000-1

Jackson J (2006) Introducing fear of crime to risk research. Risk Analysis 26(1): 253-264.

Jackson J (2007) A psychological perspective on vulnerability in the fear of crime.

Psychology, Crime and Law 15(4): 365-390.

Jackson J and Bradford B (2010) What is trust and confidence in the police? Policing: A Journal of Policy and Practice 4(3): 241-248.

Krulichová E (2019) The relationship between fear of crime and risk perception across

Europe. Criminology and Criminal Justice 19(2): 197-214.

Lizotte AJ, Krohn MD, Howell JC, Tobin K and Howard GJ (2000) Factors influencing gun carrying among young urban males over the adolescent-young adult life course.

Criminology 38(3): 811-834. 
McKinnon Edwards S. (2020). lemon: Freshing up your 'ggplot2' plots. R package version

\subsection{4. https://CRAN.R-project.org/package=lemon}

McVie S (2010) Gang membership and knife carrying: Findings from the Edinburgh Study on Youth Transitions and Crime. Edinburgh: Scottish Centre for Crime and Justice Research.

Melde C, Esbensen FA and Taylor TJ (2009) 'May piece be with you': A typological examination of the fear and victimization hypothesis of adolescent weapon carrying. Justice Quarterly 26(2): 348-376.

ONS (2017a) Public perceptions of crime in England and Wales: Year ending March 2016. Office for National Statistics: https://www.ons.gov.uk/peoplepopulationandcommunity/crimeandjustice/articles/public perceptionsofcrimeinenglandandwales/latest.

ONS (2017b) Fear of crime. Office for National Statistics: https://www.ethnicity-factsfigures.service.gov.uk/crime-justice-and-the-law/crime-and-reoffending/fear-ofcrime/latest\#full-page-history. 
ONS (2019a) Crime in England and Wales: Year ending December 2019. Office for National Statistics:

https://www.ons.gov.uk/peoplepopulationandcommunity/crimeandjustice/bulletins/crime inenglandandwales/yearendingdecember2019.

ONS (2019b) Homicide in England and Wales: Year ending March 2019:

https://www.ons.gov.uk/peoplepopulationandcommunity/crimeandjustice/articles/homici deinenglandandwales/yearendingmarch2019\#what-do-trends-in-homicide-look-like

R Core Team (2020) R: A Language and Environment for Statistical Computing. R Foundation for Statistical Computing, Vienna, Austria. URL https://www.R-project.org/.

Rengert GF and Pelfrey WV (1997) Cognitive mapping of the city center: Comparative perceptions of dangerous places. In D Weisburd and T McEwen (Eds.) Monsey: Crime Mapping and Crime Prevention (pp. 193-217). Criminal Justice Press.

RStudio Team (2015) RStudio: Integrated Development for R. RStudio, Inc., Boston, MA URL http://www.rstudio.com/.

Short, Jr JF (1984) The social fabric at risk: Toward the social transformation of risk analysis. American Sociological Review 49(6): 711-725. 
Skogan WG (2009) Concern about crime and confidence in the police: Reassurance or accountability? Police Quarterly 12(3): 301-318.

Slovic P (1987) Perception of risk. Science, 236(4799): 280-285.

Slovic P (1994) Perceptions of risk: Paradox and challenge. In B Brehmer and N Sahlin (Eds). Future Risks and Risk Management (pp. 63-78). Dordrecht: Kluwer Academic Publishers.

Slovic P, Fischhoff B and Lichtenstein S (1982) Why study risk perception? Risk Analysis 2(2): 83-93.

Spano R, Pridemore WA and Bolland J (2012) Specifying the role of exposure to violence and violent behavior on initiation of gun carrying: A longitudinal test of three models of youth gun carrying. Journal of Interpersonal Violence 27(1): 158-176.

Steinman KJ and Zimmerman MA (2003) Episodic and persistent gun-carrying among urban African-American adolescents. Journal of Adolescent Health 32(5): 356-364.

Tierney N, Cook D, McBain M and Fay C (2020) naniar: Data structures, summaries, and visualisations for missing data. $\mathrm{R}$ package version 0.5.0. https://cran.rproject.org/web/packages/naniar/index.html 
Tigri HB, Reid S, Turner MG and Devinney JM (2016) Investigating the relationship between gang membership and carrying a firearm: Results from a national sample.

American Journal of Criminal Justice 41(2): 168-184.

Traynor P (2016) Closing the 'security gap': Young people, 'street life' and knife crime. PhD Thesis, School of Law, University of Leeds.

UNICEF (2020) Worlds of influence: Understanding what shapes child well-being in rich countries. Florence: UNICEF.

Van Buuren S and Groothuis-Oudshoorn K (2011) mice: Multivariate imputation by chained equations in R. Journal of Statistical Software 45(3): 1-67. URL https://www.jstatsoft.org/v45/i03/.

Venables WN and Ripley BD (2002) Modern Applied Statistics with S (4th edition). New York: Springer.

Visser M, Scholte M and Scheepers P (2013) Fear of crime and feelings of unsafety in European countries: Macro and micro explanations in cross-national perspective. The Sociological Quarterly 54(2): 278-301. 
Wachinger G, Renn O, Begg C and Kuhliche C (2013) The risk perception paradoximplications for governance and communication of natural hazards. Risk Analysis 33(6): 1049-1065.

Warr M (2000) Fear of crime in the United States: Avenues for research and policy. Criminal Justice 4(4): 451-489.

Wickham H, Averick M, Bryan J, Chang W, D’Agostino McGowan L, François R et al. (2019) Welcome to the tidyverse. Journal of Open Source Software 4(43): 1686 https://doi.org/10.21105/joss.01686.

Wickham H (2016) ggplot2: Elegant Graphics for Data Analysis. Springer-Verlag New York. 
Table 1 Descriptive statistics

\begin{tabular}{|c|c|c|c|}
\hline & & & $\%$ \\
\hline \multirow[t]{2}{*}{ Weapon carried $(t 2)$} & Yes & 77 & 1.90 \\
\hline & No & 3,984 & 98.10 \\
\hline \multirow[t]{2}{*}{$\operatorname{Sex}(t 1)$} & Male & 1,932 & 47.57 \\
\hline & Female & 2,129 & 52.43 \\
\hline Age & & $\mathrm{M}=16.8$ & $\mathrm{SD}=3.97$ \\
\hline \multirow[t]{8}{*}{ Direct experience of violence $(t I)$} & None & 3,037 & 74.78 \\
\hline & 1 & 327 & 8.05 \\
\hline & 2 & 242 & 5.96 \\
\hline & 3 & 119 & 2.93 \\
\hline & 4 & 63 & 1.55 \\
\hline & 5 & 52 & 1.28 \\
\hline & 6 or more & 221 & 5.44 \\
\hline & $\operatorname{Mean}(S D)$ & 0.76 & 1.64 \\
\hline \multirow[t]{8}{*}{ Worry about victimisation $(t 1)$} & 0 & 649 & 15.98 \\
\hline & 1 & 312 & 7.68 \\
\hline & 2 & 1,680 & 41.37 \\
\hline & 3 & 383 & 9.43 \\
\hline & 4 & 577 & 14.21 \\
\hline & 5 & 175 & 4.31 \\
\hline & 6 & 285 & 7.02 \\
\hline & $\operatorname{Mean}(S D)$ & 2.39 & 1.65 \\
\hline \multirow[t]{5}{*}{ Trust in the police $(t I)$} & A lot & 877 & 21.60 \\
\hline & $A$ fair amount & 2,284 & 56.24 \\
\hline & Not very much or & & \\
\hline & none at all & 900 & 22.16 \\
\hline & Mean (SD) & 2.00 & 0.66 \\
\hline
\end{tabular}


Proportion of friends in trouble with the police

\begin{tabular}{llrr}
$(t 1)$ & None & 3,213 & 79.12 \\
& A few & 804 & 19.80 \\
& More than a few & 44 & 1.08 \\
& Mean $(S D)$ & 1.23 & 0.44 \\
\hline $\mathrm{M}=$ mean; SD = standard deviation & & &
\end{tabular}

$14 \mathrm{M}=$ mean; $\mathrm{SD}=$ standard deviation 
Table 2 Regression models - relationship between trust in the police (t1) and worry about victimisation (t1)

\begin{tabular}{|c|c|c|c|c|}
\hline \multicolumn{2}{|c|}{$\begin{array}{l}\text { Variable } \\
\text { (reference category) }\end{array}$} & Model 1-1 Ordinary Least Squares model & \multicolumn{2}{|c|}{ Model 1-2 Ordinal logistic regression } \\
\hline & & $95 \% \mathrm{CI}$ & $\beta$ & $95 \% \mathrm{CI}$ \\
\hline \multirow[t]{4}{*}{$(A$ lot $)$} & Some & $-0.01-0.25$ & $0.23^{* *}$ & $0.08-0.37$ \\
\hline & Not a lot or & & & \\
\hline & none & $0.06-0.37$ & $0.35^{* * * *}$ & $0.18-0.53$ \\
\hline & $\mathrm{N}$ & 4,061 & 4,061 & \\
\hline
\end{tabular}

CI: confidence interval; $* \mathrm{p}<0.05 ; * * \mathrm{p}<0.01 ; * * * \mathrm{p}<0.001$ 
Table 3 Logistic regression models - relationship between worry about violent victimisation (t1) and weapon-carrying (t2)

\begin{tabular}{|c|c|c|c|c|c|c|c|c|}
\hline \multirow{3}{*}{ Variable (reference category) } & \multicolumn{8}{|c|}{ Model } \\
\hline & \multicolumn{2}{|l|}{$2-1$} & \multicolumn{2}{|l|}{$2-2$} & \multirow{2}{*}{$\begin{array}{c}2-3 \\
\beta\end{array}$} & \multicolumn{3}{|c|}{$2-4$} \\
\hline & $\beta$ & $95 \% \mathrm{CI}$ & $\beta$ & $95 \% \mathrm{CI}$ & & $95 \% \mathrm{CI}$ & $\beta$ & $95 \% \mathrm{CI}$ \\
\hline Worry about victimisation $_{\mathrm{t} 1}$ & 0.004 & $(-0.13,0.14)$ & 0.01 & $(-0.13,0.15)$ & 0.01 & $(-0.34,0.36)$ & 0.06 & $(-0.08,0.20)$ \\
\hline \multicolumn{9}{|l|}{ Trust $_{t 1}$ (A lot) } \\
\hline Some & & & 0.46 & $(-0.27,1.2)$ & 0.38 & $(-0.83,1.59)$ & 0.58 & $(-0.15,1.3)$ \\
\hline Little or none & & & $1.20^{* *}$ & $(0.43,1.9)$ & 1.30 & $(0.06,2.54)$ & $1.4 * * *$ & $(0.64,2.2)$ \\
\hline \multicolumn{9}{|l|}{ Worry $_{t 1} \times$ Trust $_{t 1}$} \\
\hline Worry $_{t 1} \times$ Trust $_{t 1}$ (Some) & & & & & 0.03 & $(-0.37,0.44)$ & & \\
\hline $\begin{array}{l}\text { Worry }_{t 1} \times \text { Trust }_{t 1} \text { (Little or } \\
\text { none) }\end{array}$ & & & & & -0.05 & $(-0.47,0.37)$ & & \\
\hline \multicolumn{9}{|l|}{ Sex (Male) } \\
\hline Female & & & & & & & $-1.10 * * *$ & $(-1.6,-0.58)$ \\
\hline Age & & & & & & & $-0.09 *$ & $(-0.15,-0.02)$ \\
\hline Area crime deprivation & & & & & & & -0.03 & $(-0.13,0.06)$ \\
\hline
\end{tabular}




\begin{tabular}{lcccccccc} 
& \multicolumn{9}{c}{ Model } \\
& $2-1$ & & $2-2$ & & $2-3$ & & $2-4$ & \\
\hline Variable (reference category) & $\boldsymbol{\beta}$ & $\mathbf{9 5 \%} \mathbf{C I}$ & $\boldsymbol{\beta}$ & $\mathbf{9 5 \%} \mathbf{C I}$ & $\boldsymbol{\beta}$ & $\mathbf{9 5 \%} \mathbf{C I}$ & $\boldsymbol{\beta}$ & $\mathbf{9 5 \%} \mathbf{C I}$ \\
\hline $\mathbf{N}$ & 4,013 & & 4,013 & & 4,013 & & 4,013 & \\
\hline
\end{tabular}

CI: confidence interval; ${ }^{*} \mathrm{p}<0.05 ;{ }^{*} \mathrm{p}<0.01 ; * * * \mathrm{p}<0.001$ 
Table 4 Logistic regression models - relationship between experience of violence (t1) and weapon-carrying ( $\mathrm{t} 2)$

\begin{tabular}{|c|c|c|c|c|c|c|c|c|c|c|}
\hline & \multicolumn{10}{|c|}{ Model } \\
\hline & $3-1$ & & $3-2$ & & $3-3$ & & $3-4$ & & $3-5$ & \\
\hline & $\beta$ & $95 \% \mathrm{CI}$ & $\beta$ & $95 \% \mathrm{CI}$ & $\beta$ & $95 \% \mathrm{CI}^{1}$ & $\beta$ & $95 \% \mathrm{CI}^{1}$ & $\beta$ & $95 \% \mathrm{CI}^{1}$ \\
\hline Violence & $0.23 * * *$ & $(0.13,0.33)$ & $0.21 * * *$ & $(0.10,0.31)$ & 0.28 & $(0.00,0.56)$ & $0.17 * *$ & $(0.06,0.28)$ & $0.13^{*}$ & $(0.02,0.24)$ \\
\hline \multicolumn{11}{|l|}{ Trust $_{t 1}$ (A lot) } \\
\hline Some & & & 0.46 & $(-0.28,1.2)$ & 0.78 & $(-0.12,1.7)$ & 0.39 & $(-0.35,1.1)$ & 0.48 & $(-0.26,1.2)$ \\
\hline Little or none & & & $1.1 * * *$ & $(0.34,1.9)$ & 0.93 & $(-0.05,1.9)$ & $0.83 *$ & $(0.06,1.6)$ & $1.0^{*}$ & $(0.24,1.8)$ \\
\hline \multicolumn{11}{|l|}{ Violence $_{\mathrm{t} 1} *$ Trust $_{\mathrm{t} 1}$} \\
\hline Violence * Some & & & & & -0.27 & $(-0.62,0.08)$ & & & & \\
\hline Violence * Little or none & & & & & 0.05 & $(-0.27,0.37)$ & & & & \\
\hline \multicolumn{11}{|l|}{ Friends in trouble $\mathrm{e}_{\mathrm{t} 1}$ (None) } \\
\hline A few & & & & & & & $1.0 * * *$ & $(0.51,1.6)$ & $1.0 * * *$ & $(0.42,1.5)$ \\
\hline More than a few & & & & & & & $2.7 * * *$ & $(1.7,3.7)$ & $2.7 * * *$ & $(1.7,3.6)$ \\
\hline \multicolumn{11}{|l|}{ Sex (Male) } \\
\hline Female & & & & & & & & & $-1.0 * * *$ & $(-1.5,-0.43)$ \\
\hline Age & & & & & & & & & $-0.08 *$ & $-0.15,-0.01$ \\
\hline
\end{tabular}


Area crime deprivation

$\mathrm{N}$

95\% CI: $95 \%$ confidence interval; ${ }^{\mathrm{p}}<<0.05 ; * * \mathrm{p}<0.01 ; * * * \mathrm{p}<0.001$ 


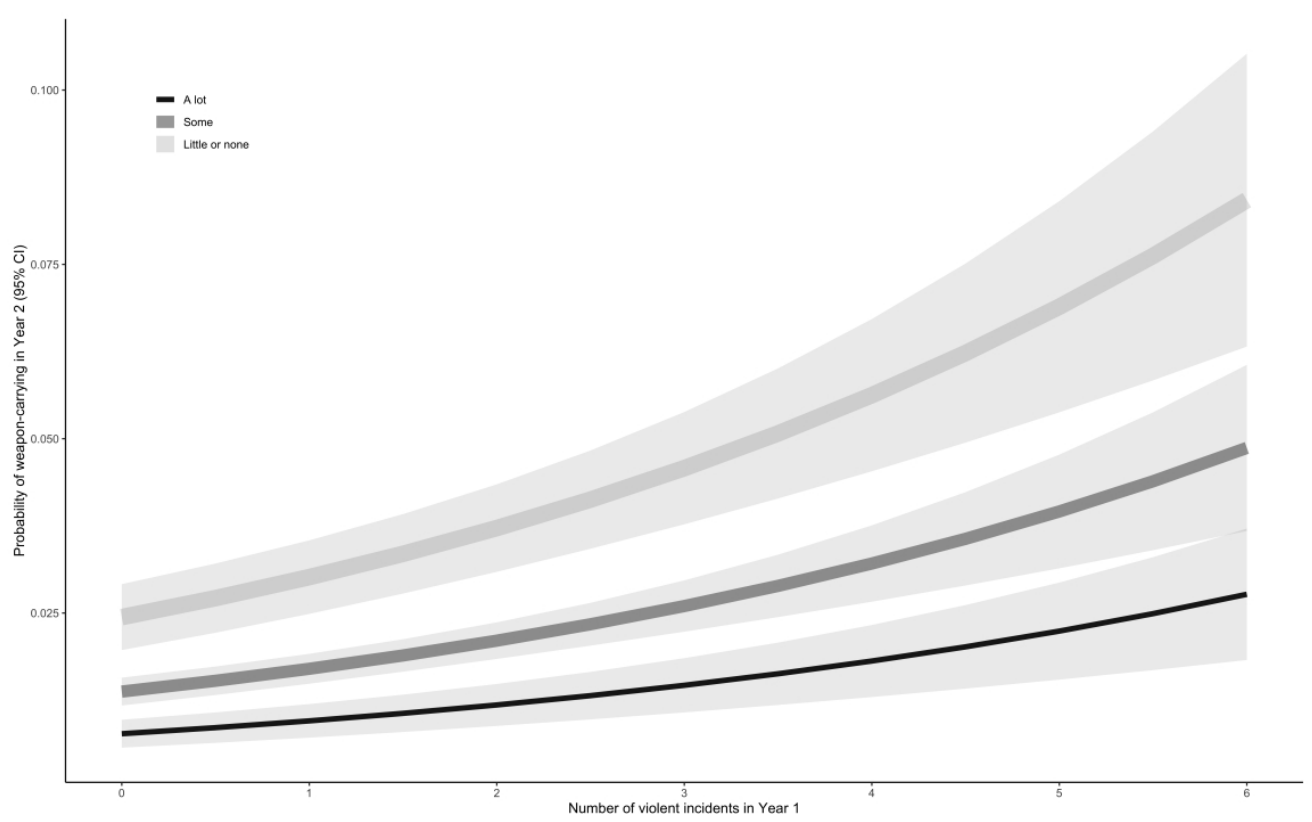

Figure 1. Relationship between direct experience of violence (t1) and predicted probability of weaponcarrying ( $t 2$ ) by trust in the police

$2474 \times 1538 \mathrm{~mm}(72 \times 72 \mathrm{DPI})$ 


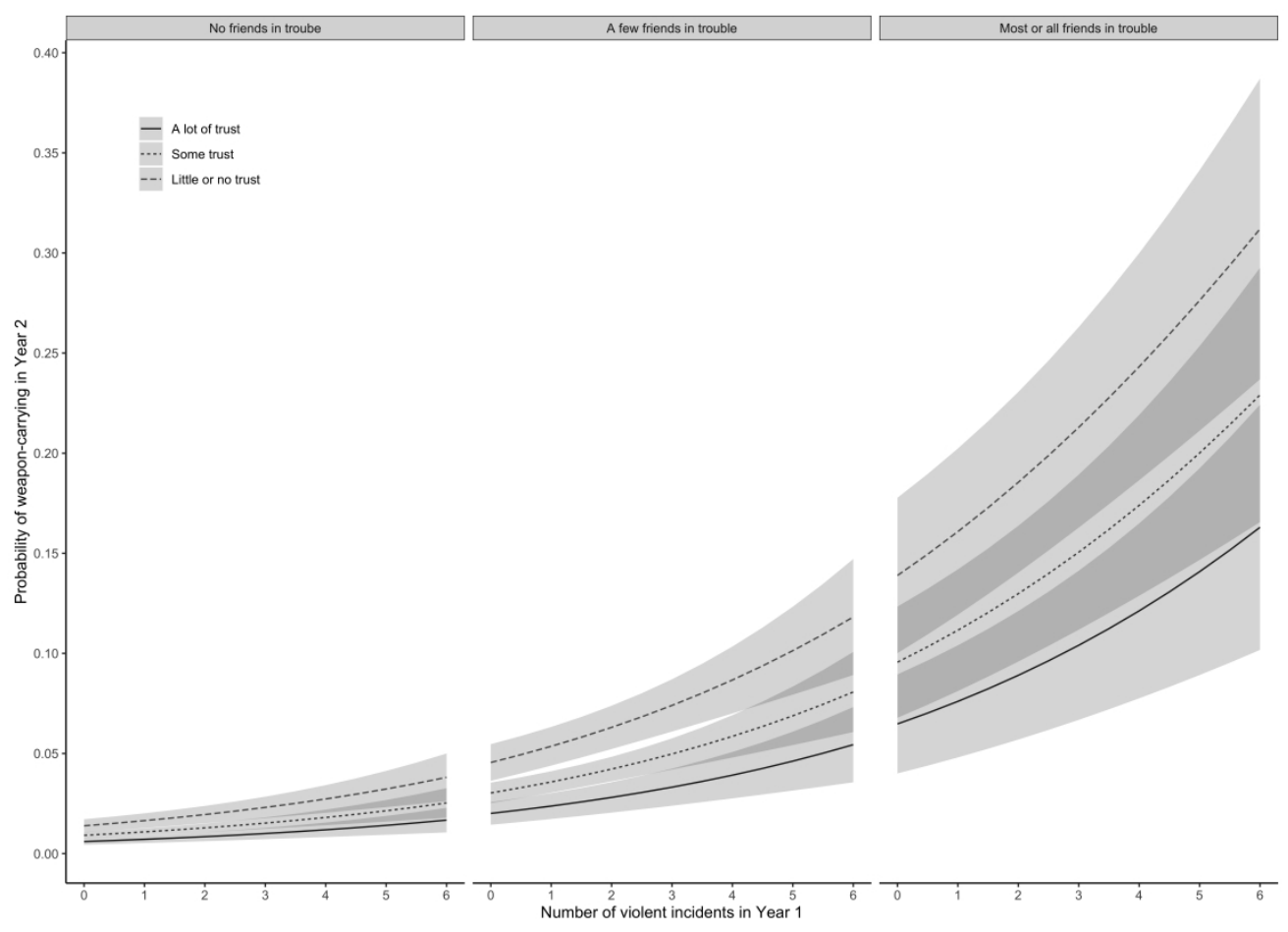

Figure 2. Relationship between direct experience of violence ( $\mathrm{t} 1$ ) and probability of weapon-carrying (t2) by trust in the police

Legend: "Each facet ("None", "A few" and "Most or all") corresponds to the proportion of respondent's friends in trouble with the police"

$2145 \times 1545 \mathrm{~mm}(72 \times 72 \mathrm{DPI})$ 
Appendix one - Models of relationship between number of violent victimization ( $\mathrm{t} 1$ ) and weapon-carrying (t2)

\begin{tabular}{|c|c|c|c|c|c|c|c|c|c|c|}
\hline Variable (reference) & b & $95 \% \mathrm{CI}$ & b & $95 \% \mathrm{CI}$ & b & $95 \% \mathrm{CI}$ & b & $95 \% \mathrm{CI}$ & b & $95 \% \mathrm{CI}$ \\
\hline Victimisation $_{\mathrm{t} 1}$ & $0.23^{* * *}$ & $(0.10,0.36)$ & $0.19^{* *}$ & $(0.06,0.32)$ & 0.03 & $-0.51,0.56$ & $0.17^{*}$ & $0.03,0.31$ & 0.12 & $(-0.02,0.26)$ \\
\hline \multicolumn{11}{|l|}{ Trust $_{\text {t1 }}$ (A lot) } \\
\hline \multicolumn{11}{|l|}{ Some } \\
\hline \multirow[t]{2}{*}{ Little or none } & & & 0.48 & $(-0.26,1.2)$ & 0.49 & $(-0.29,1.3)$ & 0.42 & $(-0.32,1.2)$ & 0.51 & $(-0.24,1.3)$ \\
\hline & & & $1.1^{* *}$ & $(0.38,1.9)$ & $0.84^{*}$ & $(0.01,1.7)$ & 0.86 & $(0.09,1.6)$ & $1.1^{* * *}$ & $(0.28,1.9)$ \\
\hline \multicolumn{11}{|l|}{ Violence $_{\mathrm{t} 1} *$ Trust $_{\mathrm{t} 1}$} \\
\hline Violence ${ }^{*}$ Some & & & & & -0.08 & $(-0.71,0.55)$ & & & & \\
\hline Violence ${ }^{*}$ Little or none & & & & & 0.31 & $(-0.25,0.87)$ & & & & \\
\hline \multicolumn{11}{|l|}{ Friends in trouble $_{\mathrm{t} 1}$ (None) } \\
\hline A few & & & & & & & $1.1^{* * *}$ & $(0.58,1.6)$ & $1.0^{* * *}$ & $(0.47,1.6)$ \\
\hline More than a few & & & & & & & $2.8^{* * *}$ & $(1.8,3.7)$ & $2.7^{* * *}$ & $(1.7,3.7)$ \\
\hline \multicolumn{11}{|l|}{ Sex (Male) } \\
\hline Female & & & & & & & & & $1.0^{* * *}$ & $(-1.5,-0.45)$ \\
\hline Age & & & & & & & & & $-0.08^{*}$ & $(-0.15,-0.01)$ \\
\hline Area crime deprivation & & & & & & & & & -0.03 & $(-0.12,0.06)$ \\
\hline
\end{tabular}

CI: confidence interval; ${ }^{*} \mathrm{p}<0.05 ;{ }^{* *} \mathrm{p}<0.01 ;{ }^{* * *} \mathrm{p}<0.001$ 
Appendix two - Models of relationship between number of violence perpetration incidents ( $\mathrm{t} 1$ ) and weapon carrying ( $\mathrm{t} 2$ )

\begin{tabular}{|c|c|c|c|c|c|c|c|c|c|c|}
\hline Variable (reference) & b & $95 \% \mathrm{CI}$ & b & $95 \% \mathrm{CI}$ & $\mathbf{b}$ & $95 \% \mathrm{CI}$ & $\mathbf{b}$ & $95 \% \mathrm{CI}$ & b & $95 \% \mathrm{CI}$ \\
\hline Victimisation $_{\mathrm{t} 1}$ & $0.29 * * *$ & $\begin{array}{l}(0.18 \\
0.40)\end{array}$ & $0.27^{* * *}$ & $\begin{array}{l}(0.15 \\
0.38)\end{array}$ & $0.24^{* * *}$ & $(0.11,0.37)$ & $0.21^{* * *}$ & $\begin{array}{l}(0.09) \\
0.33)\end{array}$ & $0.18^{* *}$ & $(0.05,0.30)$ \\
\hline \multicolumn{11}{|l|}{ Trust $_{\mathrm{t} 1}$ (A lot) } \\
\hline Some & & & 0.43 & $(-0.31,1.2)$ & 0.47 & $(-0.31,1.2)$ & 0.36 & $(-0.38,1.1)$ & 0.46 & $(-0.28,1.2)$ \\
\hline Little or none & & & $1.1^{* *}$ & $(0.34,1.9)$ & 0.82 & $(-0.02,1.7)$ & $0.82^{*}$ & $(0.05,1.6)$ & $1.0^{*}$ & $(0.24,1.8)$ \\
\hline Violence $_{\mathrm{t} 1} *$ Trust $_{\mathrm{t} 1}$ & & & & & -0.07 & $\begin{array}{c}(-0.61 \\
0.47)\end{array}$ & & & & \\
\hline Violence * Some & & & & & -0.18 & $\begin{array}{c}(-0.52 \\
0.17)\end{array}$ & & & & \\
\hline Violence ${ }^{*}$ Little or none & & & & & $0.21^{*}$ & $(0.03,0.40)$ & & & & \\
\hline \multicolumn{11}{|l|}{ Friends in trouble $_{\mathrm{t} 1}$ (None) } \\
\hline Afew & & & & & & & $1.0^{* * *}$ & $(0.48,1.6)$ & $0.93^{* * *}$ & $(0.37,1.5)$ \\
\hline More than a few & & & & & & & $2.7^{* * *}$ & $(1.7,3.6)$ & $2.6^{* * *}$ & $(1.6,3.6)$ \\
\hline \multicolumn{11}{|l|}{ Sex (Male) } \\
\hline Female & & & & & & & & & $-1.0^{* * *}$ & $(-1.5,-0.45)$ \\
\hline Age & & & & & & & & & $-0.08^{*}$ & $\begin{array}{c}(-0.15,- \\
0.01)\end{array}$ \\
\hline Area crime deprivation & & & & & & & & & -0.03 & $(-0.12,0.06)$ \\
\hline
\end{tabular}

CI: confidence interval; ${ }^{*} \mathrm{p}<0.05 ;{ }^{* *} \mathrm{p}<0.01 ;^{* * *} \mathrm{p}<0.001$ 


\section{$R$ code to reproduce results, tables and figures in manuscript 'Violence, worry and trust in the emergency of weapon-carrying'}

Data: The datasets for this analysis cannot be shared directly, but they are available without charge from UK Data Service: SN5601

https://beta.ukdataservice.ac.uk/datacatalogue/studies/study?id=5601 and SN6000

https://beta.ukdataservice.ac.uk/datacatalogue/studies/study?id=6000

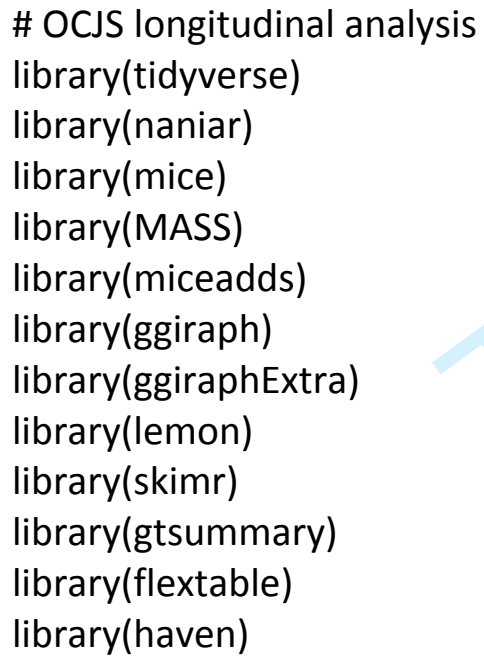

OC6<-OCJS2006 \%>\% dplyr::select(caseref, respsex, respage, g2worrc, g2worrb, g2trpol, o1vinj, o2vinj, o1vini, o2vini, n1yera18, n1yera19, h1fren, iallviol, ianypers, passault, pallviol, b2knib, b2gunb, b2knic, b2gunc, grpviol, dcri)

OC5<-replace_with_na_all(OC5, condition $=\sim . x \%$ in $\% c(-8,-9))$

OC6<-replace_with_na_all(OC6, condition $=\sim$.x \%in\% c(-8, -9))

\# Direct violence exposure

OC5\$violent1<-OC5\$grpviol \#\# violence perpetration

OC5<-OC5 \%>\% dplyr::mutate(iallviol=ifelse(iallviol>6, 6, iallviol))

OC5\$victim1<-OC5\$iallviol \# victim in past year

OC5\$direct1<-OC5\$violent1+OC5\$victim 1

OC5\$direct1<-car::recode(OC5\$direct1, "12=6;11=6;10=6;9=6;8=6;7=6")

OC6\$violent2<-0C6\$grpviol \#\# violence perpetration

OC6<-OC6 \%>\% dplyr::mutate(iallviol=ifelse(iallviol>6, 6, iallviol))

OC6\$victim2<-OC6\$iallviol \# victim in past year 
OC6 $\$$ direct2<-OC6\$violent2+OC6\$victim2
OC6\$direct2<-car::recode(OC6\$direct2, "12=6;11=6;10=6;9=6;8=6;7=6")

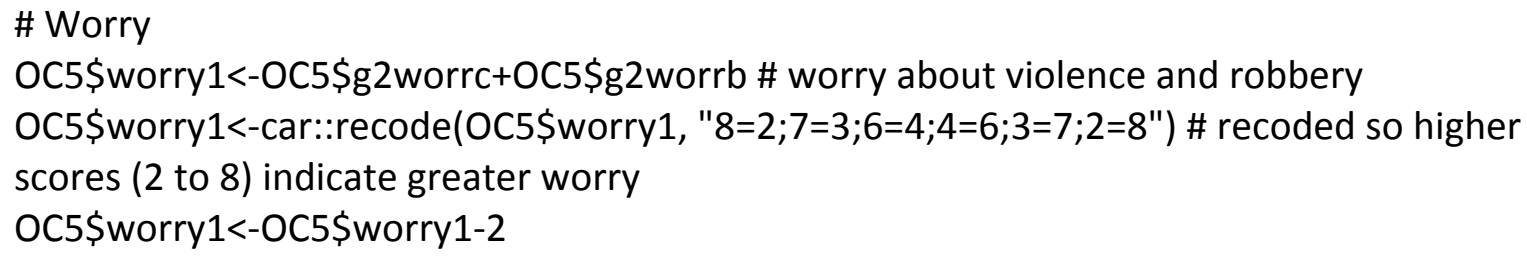

\# Slim df's

OC5s<-OC5 \%>\% dplyr::select(caseref, respage, respsex, worry1, trust1, weapon1, direct1, h1fren1, dcri1, violent1, victim1) \# Time 1 (OC5)

OC6s<-OC6 \%>\% dplyr::select(caseref, worry2, trust2, weapon2, direct2, h1fren2, violent2, victim2) \# Time2 (OC6)

OC2<-dplyr::inner_join(OC5s, OC6s, by="caseref") \# Join

OC2\$trust $1<-$ as.integer(OC2\$trust 1$)$

OC2\$direct1<-as.integer(OC2\$direct1)

\# Initiation sample only

OC2<-OC2 \%>\% dplyr::filter(weapon1==0) 
\# Remove non-response for weapon2 ( $n=5 ; 0.12 \%)$

OC2<-OC2 \% $\%$ filter(!is.na(weapon2))

\# Multiple imputation:

OC2 <- OC2 \%>\% dplyr::select(respsex, respage, worry1, trust1, h1fren1, direct1, weapon2, dcri1, violent1, victim1)

OC2_imp <- mice $(O C 2, m=20$, maxit $=20$, seed $=123$, method $=$ NULL)

OC2_imp_1<-mice::complete(OC2_imp, 1)

library(labelled)

OC2_imp\$data<-OC2_imp\$data \% $>\%$

set_variable_labels(trust1 = "Lack of trust in police", h1fren1 = "Proportion of friends in trouble with police", respsex = "Sex", respage = "Age", dcri1 = "Area crime deprivation", violent1 = "Number of violent incidents ( $\mathrm{t} 1)$ ", victim1 = "Number of violent victimisation (t1)", worry1 = "Worry about victimisation")

OC2_imp\$data<-OC2_imp\$data \% $\%$

set_variable_labels(trust1 = "Lack of trust in police", h1fren1 = "Proportion of friends in trouble with police", respsex = "Sex", respage = "Age", dcri1 = "Area crime deprivation", violent1 = "Number of violent incidents (t1)", victim1 = "Number of violent victimisation (t1)", worry1 = "Worry about victimisation")

OC2_imp $<-$ OC2_imp \% $>\%$

filter(! is.na(respsex))

OC2_imp\$data\$respsex<-as.factor(OC2_imp\$data\$respsex)

OC2_imp\$data\$respsex<-plyr::revalue(OC2_imp\$data\$respsex, c("1"="Male", "2"="Female"))

OC2_imp\$data\$trust1<-as.factor(OC2_imp\$data\$trust1)

OC2_imp\$data\$trust1<-plyr::revalue(OC2_imp\$data\$trust1, c("1"="A lot", "2"="Some", "3"="Little or none"))

\#\#\#\# Descriptive statistics

skim(OC2_imp_1)

freq(OC2_imp_1\$weapon2)

\# Hypothesis 1: Worry (t1) <- Trust (t1) in full sample

h1<-with(OC2_imp, Im(worry1 factor(trust1))) \# OLS

h1<-gtsummary::tbl_regression(h1, tidy_fun = pool_and_tidy_mice) \%>\% 


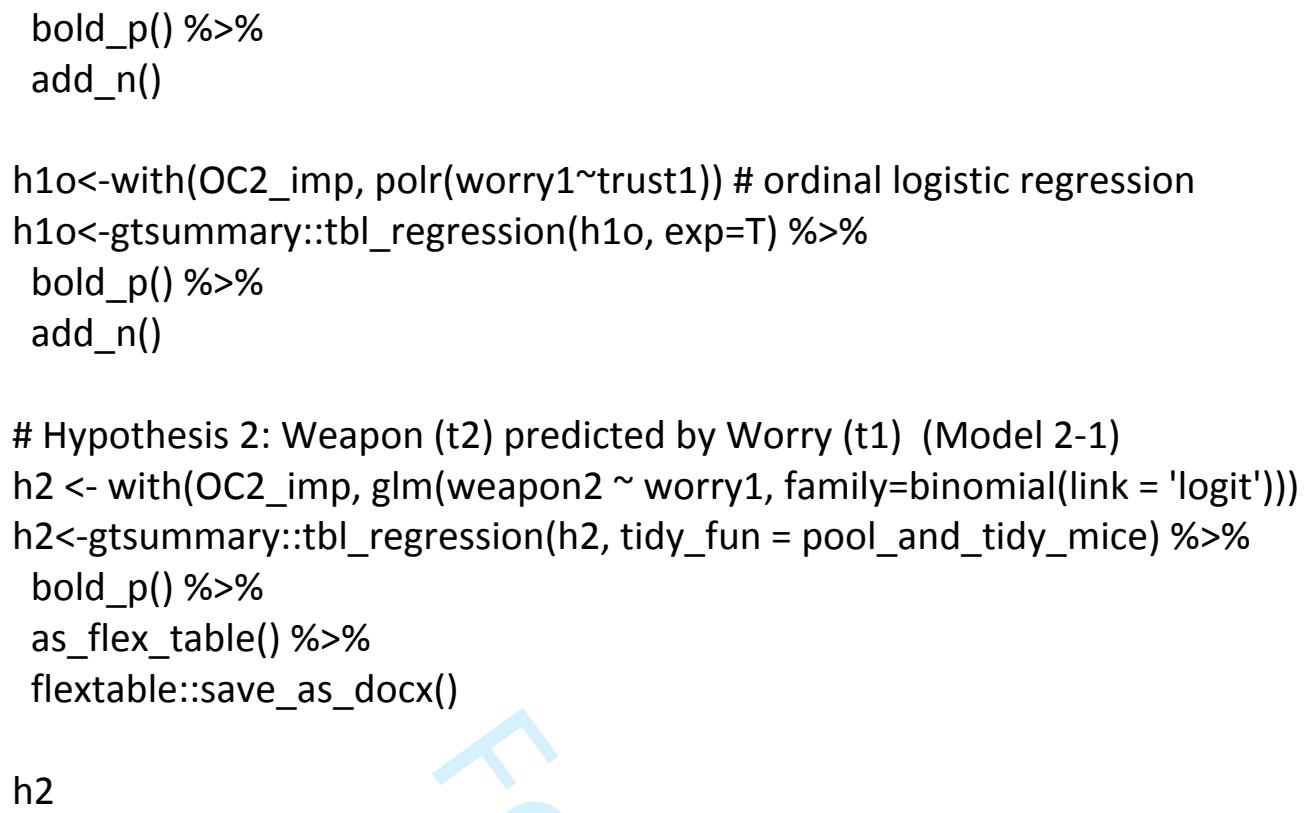




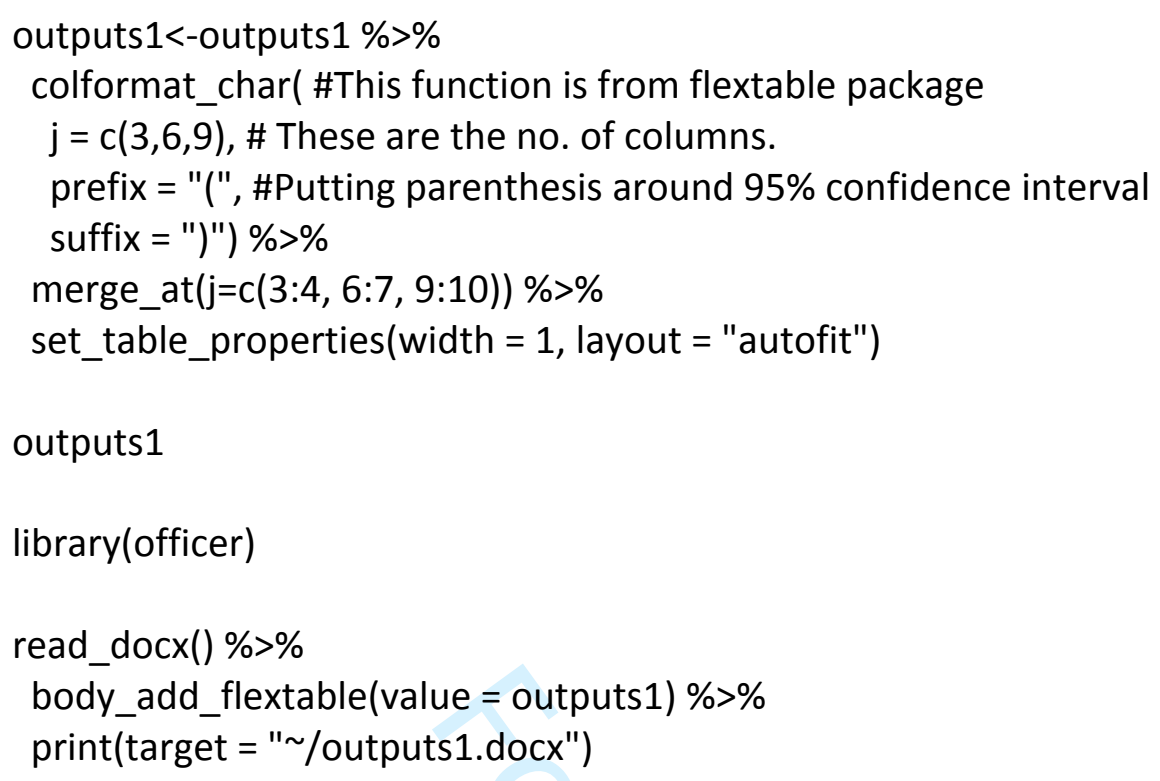

\# Hypothesis 4: Weapon (t2) predicted by experience of violence in full sample (model 3-1) h4a <- with(OC2_imp, glm(weapon2 direct1, family=binomial))

\# Hypothesis 5: Weapon (t2) - experience of violence relationship moderated by trust in the police (model 3-2)

h5a <- with(OC2_imp, glm(weapon2 direct1 + factor(trust1), family=binomial))

h5a<-gtsummary::tbl_regression(h5a, tidy_fun = pool_and_tidy_mice) $\%>\%$ bold_p()

h5a

h5ax <- with(OC2_imp, gIm(weapon2 direct1 + trust1 + direct1:trust1, family=binomial)) \#Model 3-3

h5ax<-gtsummary::tbl_regression(h5ax, tidy_fun=pool_and_tidy_mice) \%>\% bold_p()

h5ax

h5b <- with(OC2_imp, glm(weapon2 direct1 + factor(trust1) + factor(h1fren1), family=binomial)) \#Model 3-4 h5b<-gtsummary::tbl_regression(h5b, tidy_fun=pool_and_tidy_mice) \%>\% bold_p() h5b

h5c <- with(OC2_imp, glm(weapon2 direct1 + factor(trust1) + factor(h1fren1) + respsex + respage + dcri1, family=binomial)) \#Model 3-5

h5c<-gtsummary::tbl_regression(h5c, tidy_fun=pool_and_tidy_mice) \%>\% 


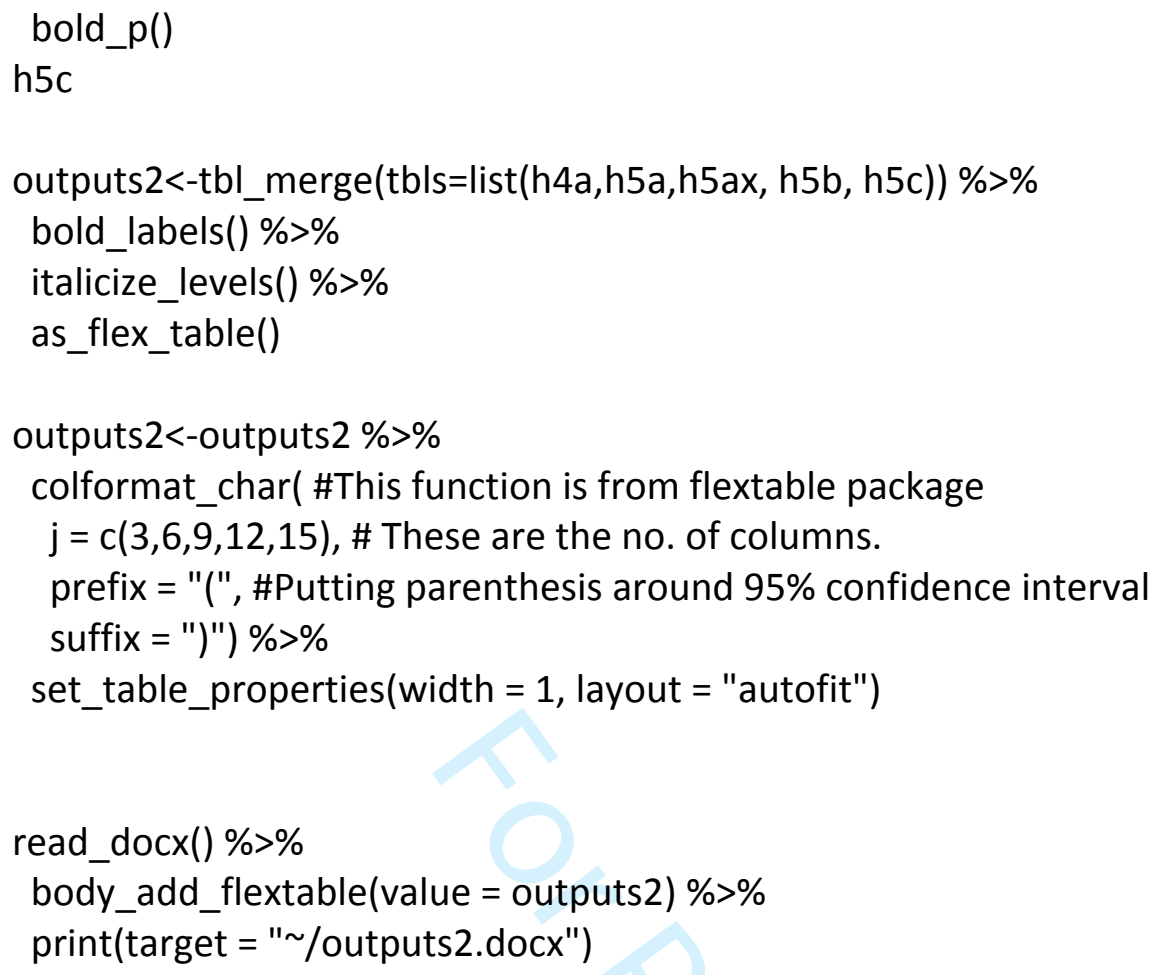




\begin{abstract}
theme (legend.title $=$ element_blank ()$)+$ scale_colour_grey(start $=0.1$, end $=0.9)+$ scale_fill_grey(start $=0.1$, end $=0.9$ )
\end{abstract}

df2\$h1fren1<-factor(df2\$h1fren1, levels=c(1:3), labels=c("No friends in troube", "A few friends in trouble", "Most or all friends in trouble"))

w<-df2 \%>\% ggplot(aes(x=direct1, $y=$ =weapon2, group=interaction(trust1, h1fren1), linetype $=\mathrm{h} 1 \mathrm{fren} 1))+$ geom_line (aes(linetype=h1fren1)) + \# geom_ribbon(aes(ymin=ymin, ymax=ymax), alpha=0.2, linetype=0) + theme_bw ()$+$ theme $($ panel.border $=$ element_blank(), panel.grid.major $=$ element_blank(), panel.grid.minor $=$ element_blank () , axis.line $=$ element_line $($ colour $=$ "black" $))+$ scale_x_continuous(breaks=seq $(0,6,1))+$ scale_y_continuous $($ breaks $=\operatorname{seq}(0,0.3,0.05)$ ) labs $(x=" N u m b e r$ of violent incidents in Year 1", $y=$ "Probability of weapon-carrying in Year $2 ")+$ theme (legend.title $=$ element_blank ()$)+$ scale_colour_grey(start $=0.1$, end $=0.5)+$ scale_fill_grey(start $=0.1$, end $=0.5$ )

m_none<-gIm(weapon2 direct1+trust1,family='binomial', OC2_imp_1, subset=h1fren1==1) m_some<-gIm(weapon2 direct1+trust1, family='binomial', OC2_imp_1, subset=h1fren1==2) m_most<-glm(weapon2 direct1+trust1, family='binomial', OC2_imp_1, subset=h1fren1==3)

none $<$-ggPredict ( $m$ _none,se $=$ TRUE, interactive $=F$, digits $=3$ )

some<-ggPredict ( $m$ _some,se $=$ TRUE, interactive $=F$, digits $=3$ )

most<-ggPredict(m_most,se=TRUE, interactive $=F$, digits $=3$ )

df_none<-as.data.frame(none\$data)

df_some<-as.data.frame(some $\$$ data)

df_most<-as.data.frame(most\$data)

plot_none<-ggplot(df_none, aes(x=direct1, $y=$ weapon2, group=trust1) $)+$ geom_line ()+ geom_ribbon(aes(ymin=ymin, ymax=ymax), alpha=0.5) + scale_y_continuous(breaks=seq $(0,0.7,0.05)$ )

plot_some<-ggplot(df_some, aes(x=direct1, y=weapon2, group=trust1)) + geom_line()+ geom_ribbon(aes(ymin=ymin, ymax=ymax), alpha=0.5) + scale_y_continuous(breaks=seq $(0,0.7,0.05)$ )

plot_most<-ggplot(df_most, aes(x=direct1, y=weapon2, group=trust1) ) + geom_line()+ 


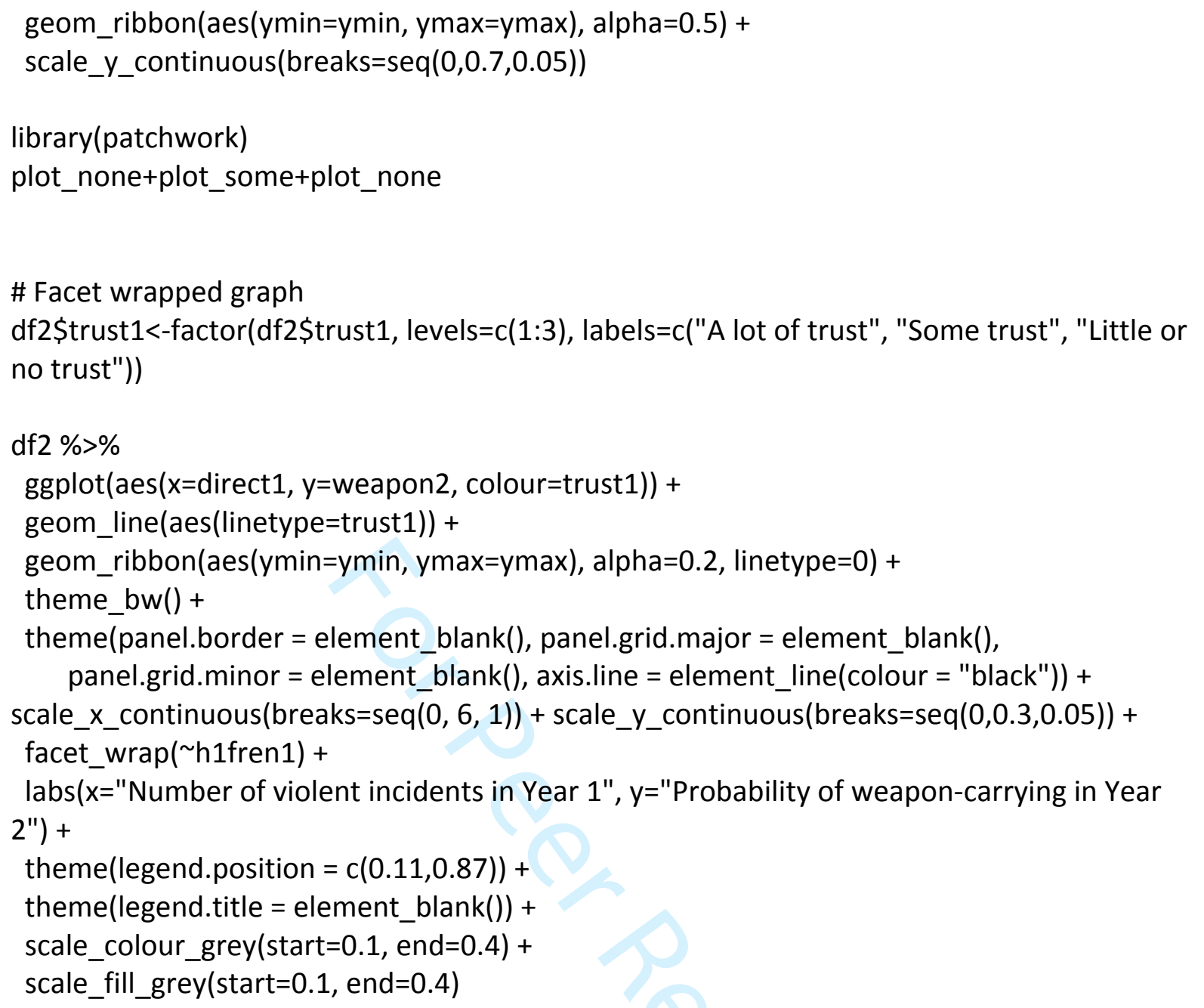




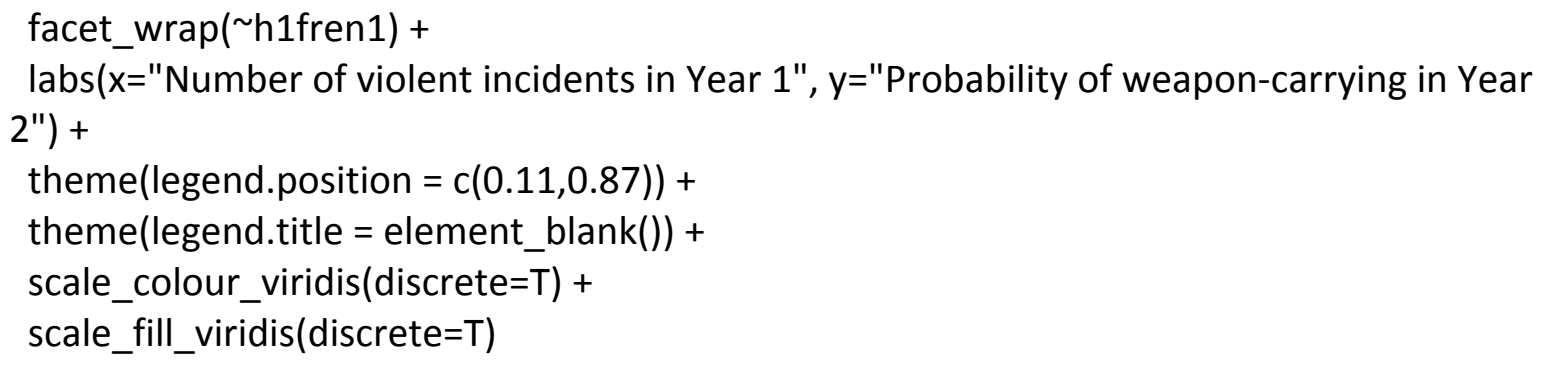




\section{$R$ code to reproduce supplementary analyses, tables and figures in manuscript as requested by reviewer for the manuscript 'Violence, worry and trust in the emergency of weapon-carrying'}

Data: The datasets for this analysis cannot be shared directly, but they are available without charge from UK Data Service: SN5601

https://beta.ukdataservice.ac.uk/datacatalogue/studies/study?id=5601 and SN6000 https://beta.ukdataservice.ac.uk/datacatalogue/studies/study?id=6000

\# OCJS longitudinal analysis

\# Additional test of models using 'violence perpetration only' and 'violence victimisation only' as predictors

\#\#\#@@ divergence from main script indicated here

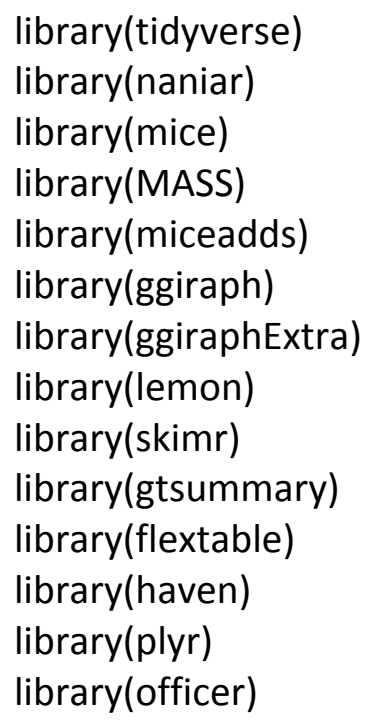

OC6<-OCJS2006 \%>\% dplyr::select(caseref, respsex, respage, g2worrc, g2worrb, g2trpol, o1vinj, o2vinj, o1vini, o2vini, n1yera18, n1yera19, h1fren, iallviol, ianypers, passault, pallviol, b2knib, b2gunb, b2knic, b2gunc, grpviol, dcri)

OC5<-replace_with_na_all(OC5, condition $=\sim . x \%$ in $\% c(-8,-9))$

OC6<-replace_with_na_all(OC6, condition $=\sim$.x \%in\% $c(-8,-9))$

\# Direct violence exposure 


\author{
OC5\$violent1<-OC5\$grpviol \#\# violence perpetration \\ OC5<-OC5 \%>\% dplyr::mutate(iallviol=ifelse(iallviol>6, 6, iallviol)) \\ OC5\$victim1<-OC5\$iallviol \# victim in past year \\ OC5\$direct1<-OC5\$violent1+OC5\$victim1 \\ OC5\$direct1<-car::recode(OC5\$direct1, "12=6;11=6;10=6;9=6;8=6;7=6")
}

OC6\$violent2<-0C6\$grpviol \#\# violence perpetration

OC6<-OC6 \%>\% dplyr::mutate(iallviol=ifelse(iallviol>6, 6, iallviol))

OC6\$victim2<-0C6\$iallviol \# victim in past year

Oc6\$direct2<-OC6\$violent2+OC6\$victim2

OC6\$direct2<-car::recode(OC6 $\$$ direct2, "12=6;11=6;10=6;9=6;8=6;7=6")

\# Worry
OC5\$worry1<-OC5\$g2worrc+OC5\$g2worrb \# worry about violence and robbery

OC5\$worry1<-car::recode(OC5\$worry1, "8=2;7=3;6=4;4=6;3=7;2=8") \# recoded so higher scores (2 to 8) indicate greater worry

OC5\$worry1<-0C5\$worry1-2

0C6\$worry2<-0C6\$g2worrc+0C6\$g2worrb

OC6\$worry2<-car::recode(OC6\$worry2, "8=2;7=3;6=4;4=6;3=7;2=8") \# recoded so higher scores (2 to 8) indicate greater worry

oc6\$worry2<-0C6\$worry2-2

\# Friends in trouble

OC5\$1fren1<-car::recode(OC5\$1fren, "5=3; 4=3")

OC6\$1fren2<-car::recode(OC6\$h1fren, " $5=3 ; 4=3 ")$

\# Trust

OC5\$trust $1<-0 C 5 \$ g 2$ trpol \# trust in police

OC6\$trust2<-0C6\$g2trpol \# trust in police

OC5\$trust1<-car::recode(OC5\$trust1, "4=3")

OC6\$trust2<-car::recode(OC6\$trust2, "4=3")

\# OC5\$trust1<-factor(OC5\$trust1, levels=c(1:4), labels = c("A lot", "Some", "Little", "None"))

\# OC6\$trust2<-factor(OC6\$̦trust2, levels=c(1:4), labels = c("A lot", "Some", "Little", "None"))

\# Weapon-carrying (T1)

OC5<-OC5 \%>\% dplyr::mutate(weapon1=ifelse(b2gunb==1 | b2knib==1, 1, 0)) \# weaponcarrying

OC6<-OC6 \%>\% dplyr::mutate(weapon2=ifelse(b2gunb==1 | b2knib==1, 1, 0)) \# weaponcarrying

\# neighbourhood crime deprivation

OC5\$dcri1<-OC5\$dcri

\# Slim df's 
OC5s<-OC5 \%>\% dplyr::select(caseref, respage, respsex, worry1, trust1, weapon1, direct1, h1fren1, dcri1, violent1, victim1) \# Time 1 (OC5)

OC6s<-OC6 \%>\% dplyr::select(caseref, worry2, trust2, weapon2, direct2, h1fren2, violent2, victim2) \# Time2 (OC6)

OC2<-dplyr::inner_join(OC5s, OC6s, by="caseref") \# Join

OC2\$trust1<-as.integer(OC2\$trust1)

OC2\$direct1<-as.integer(OC2\$direct1)

\# Initiation sample only

OC2<-OC2 \%>\% dplyr::filter(weapon1==0)

\# Remove non-response for weapon2 ( $n=5 ; 0.12 \%)$

OC2<-OC2 \% $\%$ filter(!is.na(weapon2))

\# Multiple imputation:

OC2 <- OC2 \%>\% dplyr::select(respsex, respage, worry1, trust1, h1fren1, direct1, weapon2, dcri1, violent1, victim1)

set.seed(678)

OC2_imp $<-$ mice $(O C 2, \mathrm{~m}=20$, maxit $=20$, seed $=123$, method $=$ NULL $)$

OC2_imp_1<-mice::complete(OC2_imp, 1)

library(labelled)

OC2_imp\$data<-OC2_imp\$data \% $>\%$

set_variable_labels(trust1 = "Lack of trust in police", h1fren1 = "Proportion of friends in trouble with police", respsex = "Sex", respage = "Age", dcri1 = "Area crime deprivation", violent 1 = "Number of violent incidents (t1)", victim1 = "Number of violent victimisation (t1)", worry1 = "Worry about victimisation")

OC2_imp<-OC2_imp \% $>\%$

filter(!is.na(respsex))

OC2_imp\$data\$respsex<-as.factor(OC2_imp\$data\$respsex)

OC2_imp\$data\$respsex<-plyr::revalue(OC2_imp\$data\$respsex, c("1"="Male", "2"="Female"))

OC2_imp\$data\$trust1<-as.factor(OC2_imp\$data\$trust1)

OC2_imp\$data\$trust1<-plyr::revalue(OC2_imp\$data\$trust1, c("1"="A lot", "2"="Some", "3"="Little or none")) 


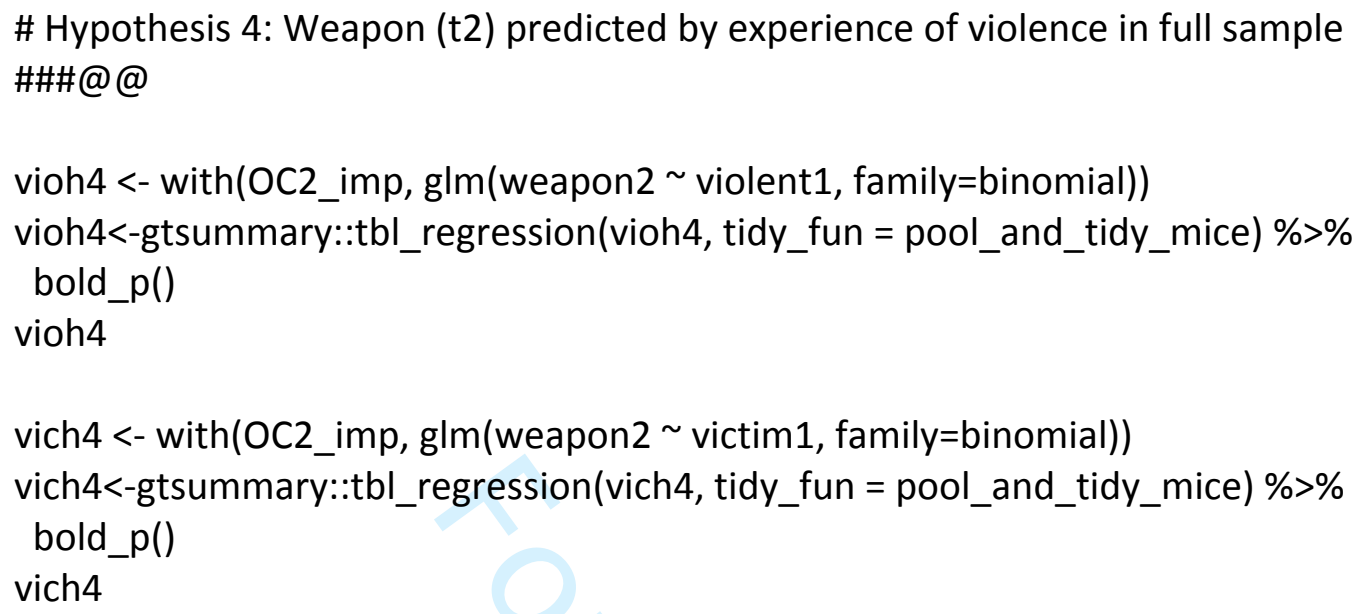

\# Hypothesis 5: Weapon (t2) - experience of violence relationship moderated by trust in the police

vioh5a <- with(OC2_imp, glm(weapon2 violent1 + factor(trust1), family=binomial)) vioh5a<-gtsummary::tbl_regression(vioh5a, tidy_fun = pool_and_tidy_mice) \%>\% bold_p()

vioh5a

vich5a <- with(OC2_imp, glm(weapon2 victim1 + factor(trust1), family=binomial)) vich5a<-gtsummary::tbl_regression(vich5a, tidy_fun = pool_and_tidy_mice) \%>\% bold_p()

vich5a

vioh5ax <- with(OC2_imp, gIm(weapon2 violent1 + factor(trust1) + victim1:trust1, family=binomial))

vioh5ax<-gtsummary::tbl_regression(vioh5ax, tidy_fun=pool_and_tidy_mice) \%>\% bold_p()

vioh5ax

vich5ax <- with(OC2_imp, glm(weapon2 victim1 + factor(trust1) + victim1:trust1, family=binomial))

vich5ax<-gtsummary::tbl_regression(vich5ax, tidy_fun=pool_and_tidy_mice) \%>\% bold_p()

vich5ax

vioh5b <- with(OC2_imp, gIm(weapon2 violent1 + factor(trust1) + factor(h1fren1), family=binomial)) 


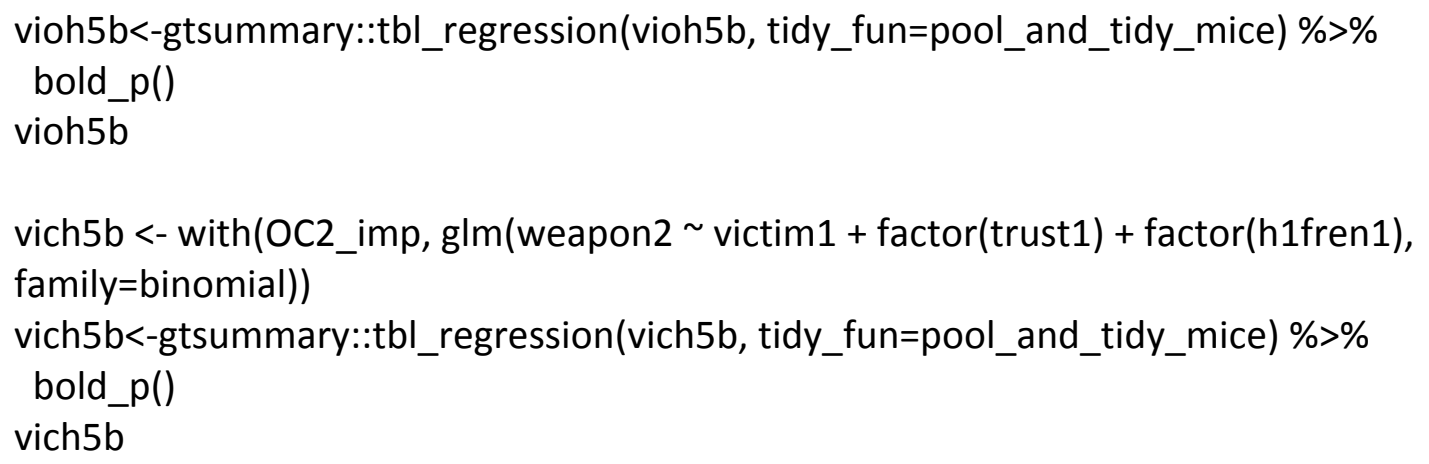




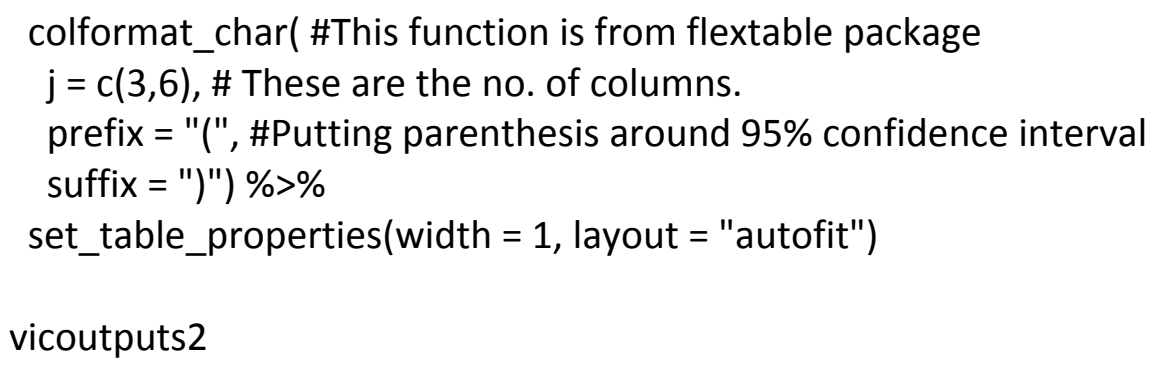

